\title{
Advances in Superplasticity and in Superplastic Materials
}

\author{
Oleg D. SHERBY
}

Department of Materials Science and Engineering, Stanford University, Stanford, CA 94305-2205, U.S.A.

\begin{abstract}
Superplasticity and superplastic materials have gained considerable attention in recent years. The number of publications in these fields is increasing rapidly attesting to the current strong interest in these subjects. It can be stated that the technology of making complex shaped components by gas pressure techniques through use of superplastic sheet has come of age. On the other hand, bulk superplastic forming is still is its infancy. Considerable progress has been made in understanding the processes occurring in fine structure superplasticity and in internal stress superplasticity. Besides the traditional superplastic alloys based on nickel, titanium and zinc, new alloys have been developed which included microduplex stainless steel, aluminum-lithium and aluminum-magnesium alloys, mechanically alloyed aluminum, whisker and particle reinforced metal matrix composites, aluminum bronze and yttria-stabilized zirconia ceramic polycrystals.
\end{abstract}

KEY WORDS: superplasticity; superplastic materials; gas pressure techniques; bulk superplastic forming; microduplex stainless steel; $\mathrm{Al}-\mathrm{Li}$ alloy; $\mathrm{Al}-\mathrm{Mg}$ alloy; mechanical alloyed $\mathrm{Al}$; whisker; Al-bronze; particle reinforced metal matrix composites; zirconia ceramics.

\section{Introduction}

It is with great pleasure that $I$ address you today. I am highly honored to be a Yukawa Memorial Lecturer. Although I have never met Mr. Yukawa, it is clear that he was a man with great vision, determination and courage. His contributions to enhancing steel production and steel metallurgy are truly remarkable. The seeds he planted have lead to the current world leadership by your nation in this highly important high technology field. I wish I could have known Mr. Yukawa personally. Today's talk is, of course, dedicated to him. Before I begin my formal lecture, I would to say that my association with Japan has extended over a long period of time. Let me elaborate. My father was a Russian who lived in Vladivostok, Siberia. Since there were no good schools there, his father sent him to Japan for an education. During the period 1902 to 1908 (age 9 to 15), he first went to a French-speaking Catholic school in Nagasaki and then to an English-speaking Catholic school in Yokohama. In Nagasaki he was taken care of by Aunt Christine, his Japanese aunt (wife of his father's brother). After returning to Russia, and participating in World War I, he escaped from Siberia (with my mother) when the communists came into power there. My parents went to Shanghai where I was born. During my youth, we often went to Japan to visit my father's aunt in Nagasaki. They were memorable visits. When the Japanese occupied China, we left Shanghai and emigrated to the United States. That was in 1938, and on our way to our new home in California, we saw Aunt Christine for the last time. Forty years later, I returned to Japan, and with Professors H. Nakamura and S. Umekawa, we revisited Nagasaki, and found Aunt Christine's home site. It was a touching ex- perience. Today, I have returned for my third visit to your country as a researcher-professor, and I am delighted with this opportunity to be with you again.

Superplasticity and superplastic materials have been subjects of considerable discussion in recent years. Not only of great scientific interest, these areas have gained status industrially through the creation of novel technological materials which involve new production procedures. Superplastic forming permits the manufacture of complicated shaped products in such a way that the energy-intensive processes of machining and joining can be minimized and often even eliminated. What is superplasticity? In its simplest definition, superplasticity describes the ability of crystalline materials to deform extensively in tension, typically over several hundred percent, with only a very gradual formation of a neck. Superplastic materials have this characteristic because they exhibit flow stresses, $\sigma$, which are highly sensitive to the rate of deformation, $\dot{\varepsilon}$. That is, they have a high strain-ratesensitivity exponent, $m$, in the relation $\sigma=K \dot{\varepsilon}^{\mathrm{m}}$, with values typically equal to 0.5 or greater. When the strain-rate-sensitivity exponent is equal to unity, the material is said to exhibit Newtonian-viscous behavior. The material can then behave like many non-crystalline materials such as heated glass. This is a desireable goal to achieve in superplastic crystalline materials although it is rarely observed. It is an important area worthy of considerable research and development studies.

\section{Historical}

The history of superplasticity has been reviewed by several authors. ${ }^{1-4)}$ Although superplasticity is believed to be a recently-discovered phenomenon, it has had a fairly long history, perhaps even to ancient 
times. It would appear, however, that the first documented description of a superplastic material occurred 76 years ago. ${ }^{4)}$ This description is attributed to Bengough in Great Britain, ${ }^{5)}$ who, in 1912, stated that " a certain special brass which he had examined pulled out to a fine point, just like glass would do, having an enormous elongation ". The special brass was, in fact, a duplex alpha-plus-beta brass. The two phases would stabilize the fine grain size likely developed, resulting in a high strain-rate sensitive material. Geckinli6) speculates that since some ancient brasses used in Turkey in the early Bronze period (around $2200 \mathrm{BC}$ ) had ten percent arsenic, they too could likely have been superplastic. This is because a $\mathrm{Cu}-10 \mathrm{As}$ alloy will consists of two phases and the metal-smiths of ancient times could well have hand forged intricate shapes from such arsenic brasses at temperatures where the material could have flowed in a superplastic manner. The current strong impetus on studies in superplasticity, however, can be said to have started with the work of Backofen and his colleagues, ${ }^{7)}$ in 1964, when they described and demonstrated the superplastic characteristics of a $\mathrm{Zn}-\mathrm{Al}$ alloy. At the present time, the topic of superplasticity has been of sufficient general scientific interest that a world record for maximum tensile elongation in crystalline solids has been recognized in the Guiness Book of World Records. ${ }^{8}$ (The world record held by Ahmed and Langdon") in a Pb-Sn alloy (4 850\%) has been recently surpassed by Higashi et al. ${ }^{10)}$ in a commercial aluminum bronze $(5500 \%)$. Both these samples are shown in Fig. 1. In general, such high elongations are not required in making desireable superplastic components.

The success achieved in the implementation of superplasticity to the manufacture of titanium, nickel and aluminum base alloys can be related to the intensive research activities in the field of superplasticity. This is well illustrated by observing the trend in the number of publications per year as a function of time. Fig. 2 illustrates this trend for publications on finestructure superplasticity since 1960.4) As can be seen, no publications appeared in 1963, only one in 1964, and only two in 1965. Since then, the growth rate in superplasticity studies has been quite remarkable. In 1970 , there were about 40 publications, in 1975 about 90 , in 1980 about 120 , and in 1985 about 200. The interest in this area continues unabated.

Since the 1982 International Conference on Super- plastic Materials in San Diego, California, ${ }^{11}$ a number of other international symposia have been held. Superplastic forming was the topic of a symposium held in Los Angeles in 1984.12) A conference on superplastic aerospace aluminum alloys was held in Cranfield, U.K., in July 1985, ${ }^{13)}$ and a general conference on superplasticity was held in Grenoble, France in September 1985. ${ }^{14)}$ AGARD/NATO selected superplasticity as one of their lecture series in 1987.15) An international symposium was held in Phoenix, Arizona, U.S.A., January 26-28, 1988 on the subject of superplasticity in aerospace alloys. ${ }^{16}$ ) Bilateral symposia on superplasticity between China and Japan have been held in Beijing in 1985'17) and in Yokohama in 1986. ${ }^{18)}$ In the first Cino-Japan Symposium, 32 separate papers were presented over a 4 day period with considerable emphasis on superplastic ferrous and aluminum base alloys.

\section{Types of Superplasticity and Their Struc- ture Requirements}

There are two types of superplastic behavior in crystalline solids. One is known as fine-structure superplasticity (FSS), and the other is known as internal-stress superplasticity (ISS). Fine-structured (grained) superplastic materials have a strain-ratesensitivity exponent equal to about 0.5 (in most cases), and deform principally by a grain-boundary sliding mechanism. Internal-stress superplastic materials are usually characterized by a strain-rate-sensitivity exponent of unity, i.e., they exhibit Newtonian-viscous behavior. Such superplastic materials need not be fine-grained and they generally deform by a slip deformation mechanism. These two distinctly-different superplastic systems will be described in some detail in the following two sections.

\subsection{Fine Structure Superplasticity (FSS)}

Most crystalline materials that are superplastic have this unique property because they are finegrained materials. The most common superplastically formed products are made from fined grained sheets. The principal method is by blow forming, gas pressure being applied on one side of the sheet, whereby the sheet plastically flows into a die of predetermined shape and complexity. An example of a superplastically formed component, made from an Al-Li alloy, is shown in Fig. 3. This selected com-
Fig. 1.

Superplastic behavior of a fine-grained $\mathrm{Pb}-62 \% \mathrm{Sn}$ alloy (4850\% elongation) by Ahmed and Langdon is shown in the top figure.

The superplastic behavior of a fine grained commercial Al bronze $(5500 \%)$ by Higashi $e t$ al. is illustrated in the bottom figure.

Note: Scales are identical.

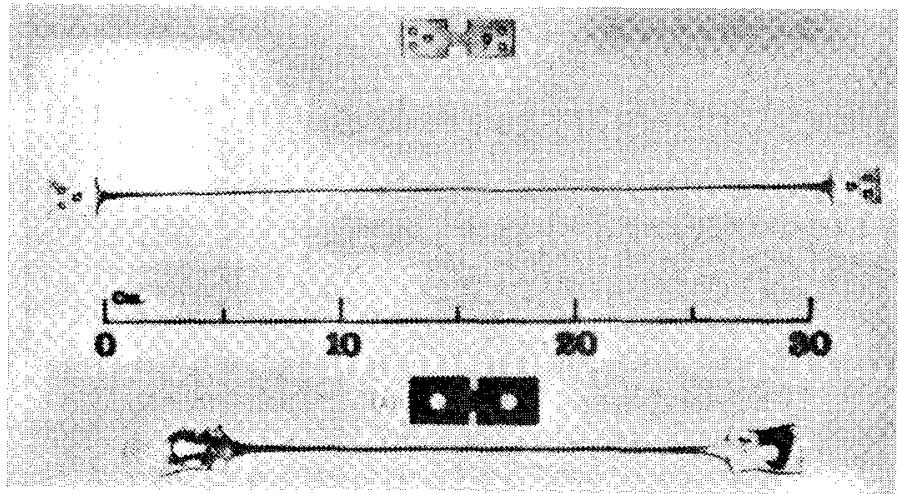


ISIJ International, Vol. 29 (1989), No. 8

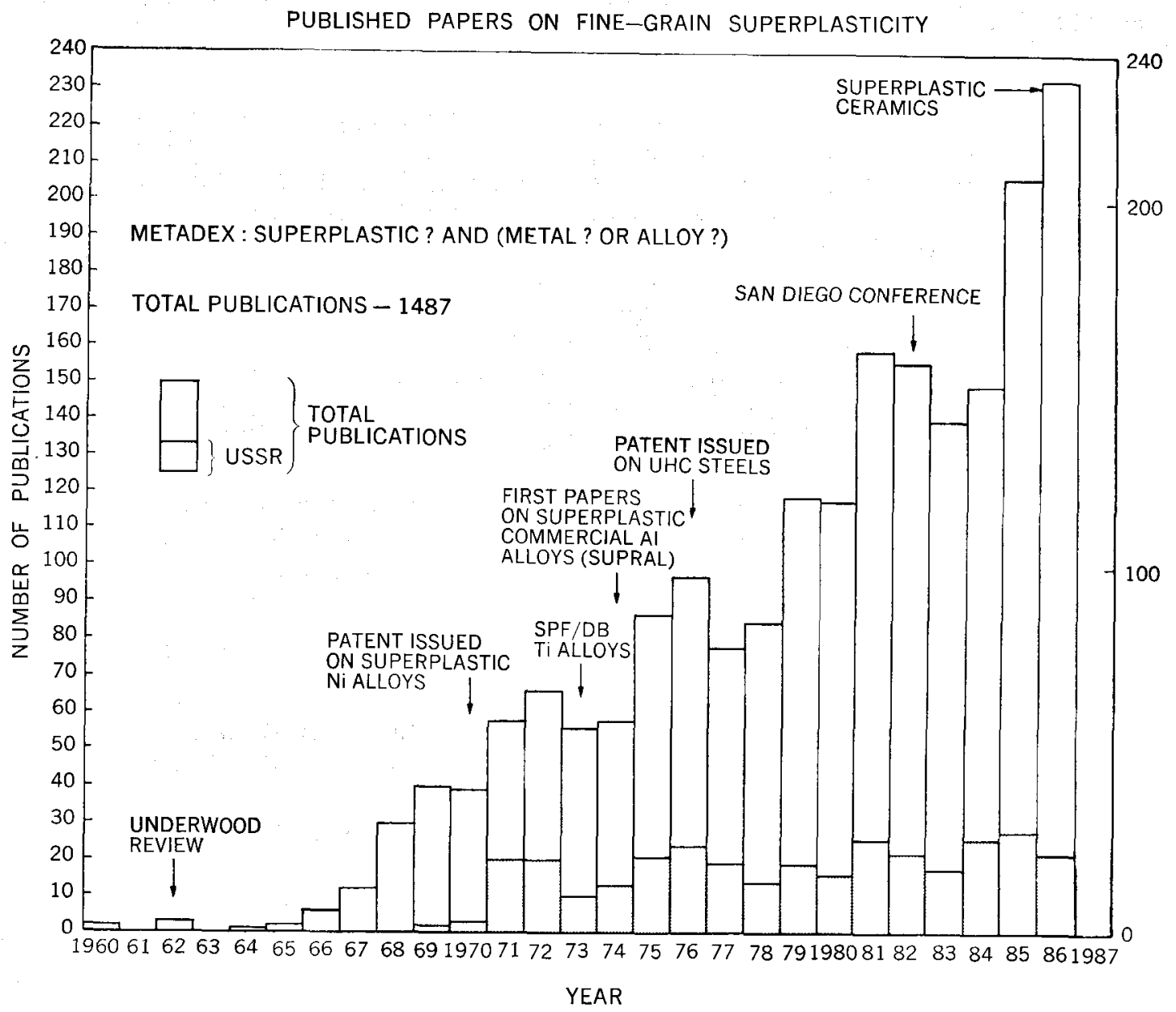

Fig. 2. Published papers on fine-grained superplasticity from 1960 showing highlights from the last 25 years.

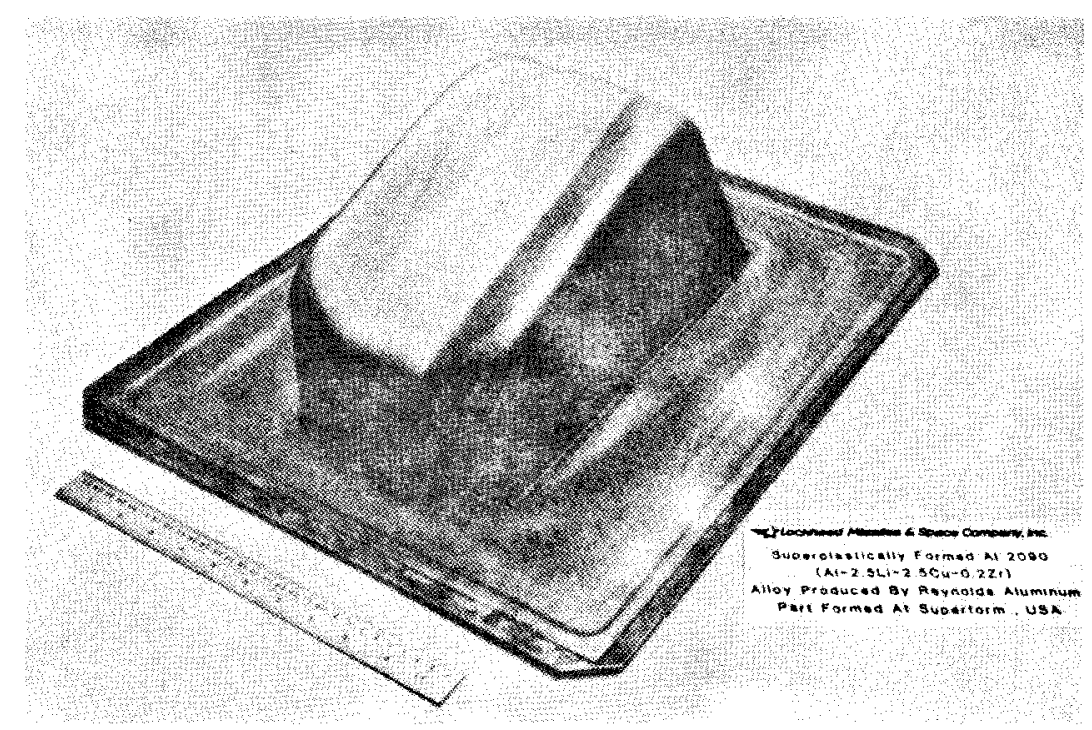

Fig. 3.

Superplastically formed components from a fine-grained Al-Li alloy (Al-2090). Courtesy of J. Wadsworth (Ref. 19)). ponent, a parachute headbox container, was successfully formed under commercial conditions using the male forming technique. ${ }^{19)}$ The composition of the $\mathrm{Al}-\mathrm{Li}$ alloy is $2.6 \% \mathrm{Cu}, 2.4 \% \mathrm{Li}$ and $0.18 \% \mathrm{Zr}$, and is of special interest because of its precommercial status as Al-2090. Another example of a superplastically formed component is shown in Fig. 4. The article is a stainless steel component used as sanitary ware in commercial aircraft. The steel is a $25 \% \mathrm{Cr}-$
$5 \% \mathrm{Ni}$ microduplex alloy and the article was manufactured by Incoform of Birmingham, U.K. A variation of the process of gas pressure forming is the superplastic-forming and diffusion bonding process (SPF/DB). Many sandwich structure products are made by this process with fine-grained titanium alloys, usually the Ti-6Al-4V alloy. ${ }^{203}$ An example of the procedure to form a four sheet SPF/DB structure is shown in Fig. 5. ${ }^{21)}$ The diffusion bonding is readily 
achieved because of the fine-grain size and because the oxide diffusion barrier in titanium dissolves at the temperature of processing, about $925^{\circ} \mathrm{C}$.

It is quite well accepted that superplastic gas pressure forming of fine-grained sheet materials has come of age, and is in "a state of maturity". ${ }^{22)}$ Another method of superplastically forming parts is by pressforging of bulk material into complex dies. Such processing of ultra-fine grained materials is still in the early stages of development. The best known example of a product made in this manner is a disk with turbine blades made from a fine-grained nickel base alloy.23) An example is shown in Fig. 6. Another possible application of press forging superplastic materials is the production of gears. Fig. 7 illustrates a bevel gear warm forged from a fine-grained ultrahigh carbon steel (UHCS). ${ }^{12}$ An additional advantage of using superplastic ultrahigh carbon steels is that the carburizing step in normal gear production is eliminated. In UHC steels, the fine structure developed for superplasticity can also lead to consider- ably better room-temperature properties than with traditional gear steels. Manufacture of die components by superplastic hobbing is another application which is particularly amenable to fine grained high carbon steels. Pearce ${ }^{24)}$ has performed investigations in this promising field. Conventional die steels have been made superplastic by thermal cycling heat treatments and these steels have been reported by Yang Chun-Xiao. ${ }^{25}$ ) These steels exhibit high strain-rate sensitivity at $800^{\circ} \mathrm{C}$ and superplastically formed dies have been made for use in die casting and in cold extrusion operations.

Very limited quantitative studies have been made in evaluating the variables involved in making bulk products from superplastic materials. It is clear, however, that this field is worthy of much quantitative study. Of special potential significance is the possibility of achieving new bulk shapes through powder metallurgy with the use of superplastic fine-structure powders. Another area related to bulk forming is the preparation of laminated composites based on

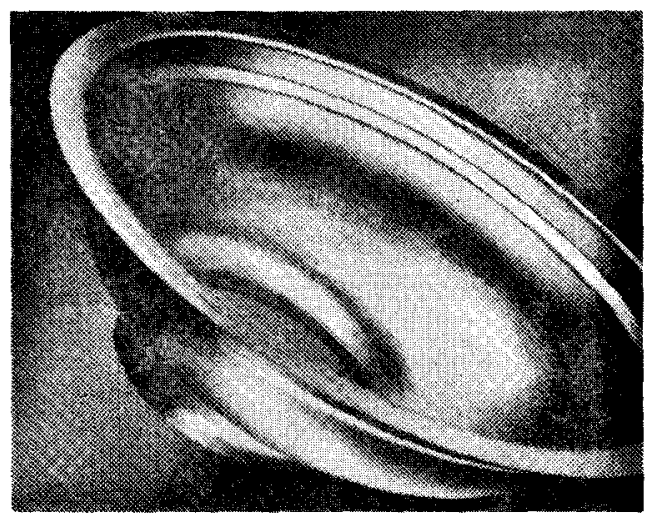

Fig. 4.

Superplastically formed component from a microduplex stainless steel.

Courtesy of D. Stephen, Incoform Ltd.

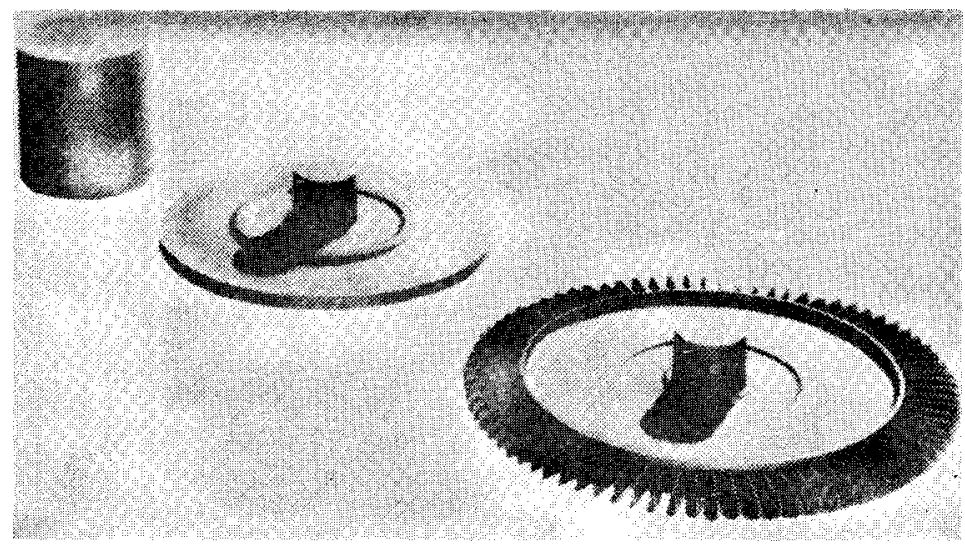

Left: Original powder metallurgy IN 100 billet

Genter: Powder metallurgy billet pressed into disk shape

Right: Disk-shaped billet superplastically pressed into disk and turbine blades

Fig. 6. Net shape forming of an ultrafine-grain-size, nickel-base alloy by superplastic forming in two stages.

Courtesy of J. Moore and R. Athey, Pratt and Whitney, Florida (AF Contract F33615-72-C2177).

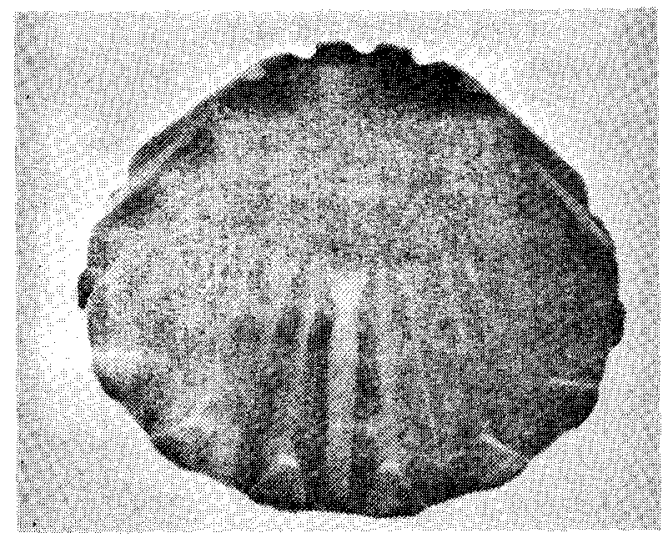

Composition of the forging: $1.25 \% \mathrm{C}$ steel Forging temperature: $650^{\circ} \mathrm{C}$

Fig. 7. Warm precision forging of an ultrahigh carbon steel billet into a bevel gear. wich part.

Courtesy of B. W. Kim and S. Agrawal. 
dissimilar materials where one of the materials is superplastic. Examples in powder metallurgy processing under superplastic conditions, and the preparation of laminated composites with superplastic materials, will be described later in the paper.

\subsubsection{Structural Prerequisites for FSS Materials}

The structural prerequisites for developing superplastic materials have been well developed for metal base fine-grained materials. They are, however, less clearly developed for non-metallic fine-grained materials. In the following, a number of prerequisites are given for the development of fine-structure superplastic materials.

\section{(1) Fine Grain Size}

One of the major requirements for fine structure superplasticity is that the grain size, $d$, should be small. Typically, the grain size should be on the order of 1 to $5 \mu \mathrm{m}$. This is because the strain rate increases with a decrease in grain size when grain boundary sliding is the rate-controlling process. Thus, grain size refinement represents a powerful method of increasing the strain rate for superplastic forming of alloys and for simultaneously maintaining a low flow stress.

\section{(2) Presence of Second Phase}

Almost invariably, it is very difficult to observe superplasticity in single phase materials because grain growth is too rapid at temperatures where grain boundary sliding occurs. Therefore, in order to maintain a fine grain size in the superplastic forming range, the presence of a second phase at grain boundaries is required. For this reason, many superplastic materials are based on eutectoid (e.g., Fe-C), eutectic (e.g., $\mathrm{Al}-\mathrm{Ca}$ ), or monotectoid (e.g., $\mathrm{Zn}-\mathrm{Al}$ ) compositions. These materials can be thermomechanically processed to develop fine, equiaxed, two phase structures. Inhibition of grain growth is usually improved if the quantity of second phase is increased, provided that the size of second phase is fine and its distribution is uniform (e.g., hypereutectoid Fe-C alloys). The only ceramic base-material made superplastic to date is based on the above principle. It is an yttria-stabilized zirconia polycrystal consisting of $90 \%$ tetragonal phase zirconia and $10 \%$ cubic-phase zirconia. Wakai et $a l .{ }^{26)}$ showed that this material, when $d=0.3 \mu \mathrm{m}$, was superplastic at $1450^{\circ} \mathrm{C}$ with $120 \%$ elongation and a strain-rate-sensitivity exponent of 0.5 , Fig. 8 illustrates this remarkable result. Apparently, this technology is already being used to manufacture ceramic components. In a recent paper by Wakai and Kato, tensile elongations above $200 \%$ were reported for a similar microduplex zirconia material. ${ }^{27}$ )

\section{(3) Strength of the Second Phase}

There is evidence to suggest that the relative strengths of the matrix and second phase constitute an important parameter in the control of cavitation during superplastic flow. Many fine-grained aluminum and copper base alloys are susceptible to cavitation during superplastic deformation and this is likely due to the large difference in strength between the matrix and the second hard phase. On the other hand, fine-graincd $\mathrm{Ti}-6 \mathrm{Al}-4 \mathrm{~V}$ and hypereutectoid $\mathrm{Fe}-\mathrm{C}$ alloys do not exhibit cavitation. This may be attributed to the nearly similar strengths of the two phases making up the alloys at the temperature where superplastic flow is observed.

\section{(4) Size and Distribution of Second Phase}

If the second phase is considerably harder than the matrix phase it should be distributed uniformly and in fine particle form within the matrix. In the form of fine, but hard, particles, cavitation during superplastic flow is inhibited by various recovery mechanisms occurring in the vicinity of the particle. Chung and Cahoon ${ }^{28)}$ have shown how hard but fine silicon particles can minimize cavitation during superplastic flow of a fine-grained Al-Si eutectic alloy. Coarse particles, on the other hand, can lead to cavitation. For example, in white cast iron, cavitation occurs at the interface of coarse eutectic carbides $(\geq 10 \mu \mathrm{m})$ and the matrix during superplastic flow at $700^{\circ} \mathrm{C}$. These large carbides cannot be refined by traditional thermal-mechanical working. It is possible, however, through rapid solidification technology and powder metallurgy, to obtain fine carbide particles distributed in the iron matrix in white cast irons. Ruano et al. ${ }^{29)}$ showed that a $3 \% \mathrm{C}$ white cast iron produced in this way revealed virtually no cavitation after superplastic deformation, even after large tensile elongations in excess of $1000 \%$ elongation.

Maehara ${ }^{30)}$ has a unique and compelling view on

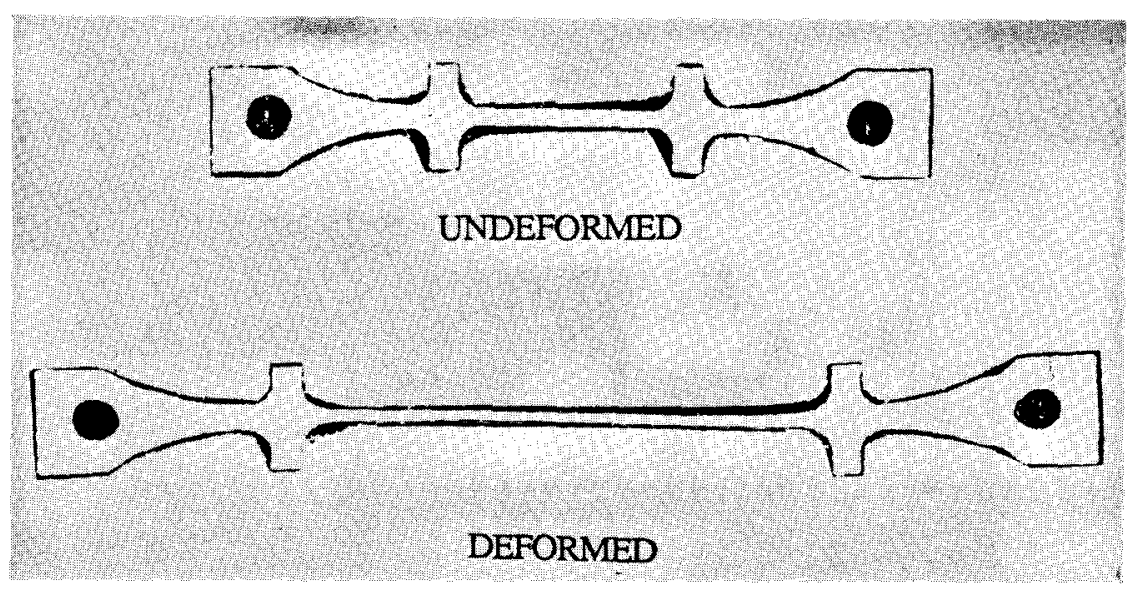

Fig. 8.

The first demonstration of true superplastic behavior in a ceramic by Wakai et al. in an yttria-stabilized, fine-grained zirconia. 
the influence of hard particles on enhancing superplasticity in stainless steels. He investigated a number of stainless steels and concluded that the optimal superplastic condition is achieved when a fine distribution of hard delta phase exists in the austenitic matrix. He obtained over $2000 \%$ elongation at $950^{\circ} \mathrm{C}$ and at a strain rate of $2 \times 10^{-3} \mathrm{~s}^{-1}$ for a stainless steel of composition $25 \% \mathrm{Cr}, 7 \% \mathrm{Ni}, 2.8 \% \mathrm{Mo}$, $0.85 \% \mathrm{Mn}, 0.5 \% \mathrm{Si}, 0.5 \% \mathrm{Cu}, 0.3 \% \mathrm{~W}$, and 0.14 $\%$ N. Maehara considers that optimal superplastic behavior is achieved when recrystallization is occurring during deformation. He contends that recrystallization will only occur when a sufficiently large amount of hard, small particles exists (about 30\% of sigma phase). The sigma phase particles act as sites for recrystallization due to severe heterogeneous deformation around the hard particles. Maehara concludes that soft particles distributed in a hard matrix will not exhibit superplastic behavior. His model is depicted schematically in Fig. 9. His model certainly has considerable merit. It may not be applicable in other two phase systems, however, such as in eutectic composition white cast iron. Kum et al., ${ }^{31)}$ have shown that such a material, which consists of a continuous phase of relatively hard cementite $(60 \%$ $\mathrm{Fe}_{3} \mathrm{C}$ ) with a discontinous soft phase of alpha iron, is superplastic at $700^{\circ} \mathrm{C}$. The strain-rate-sensitivity exponent was about 0.5 and elongations in the order of $150 \%$ were observed.

\section{(5) Nature of the Grain Boundary Structure}

The grain boundaries between adjacent matrix grains should be high angle (i.e., disordered). This is because grain boundary sliding (G.B.S.) is generally the predominant mode of deformation during superplastic flow. Low angle boundaries, as often obtained during warm working, do not readily slide under the appropriate shearing stresses. Structures

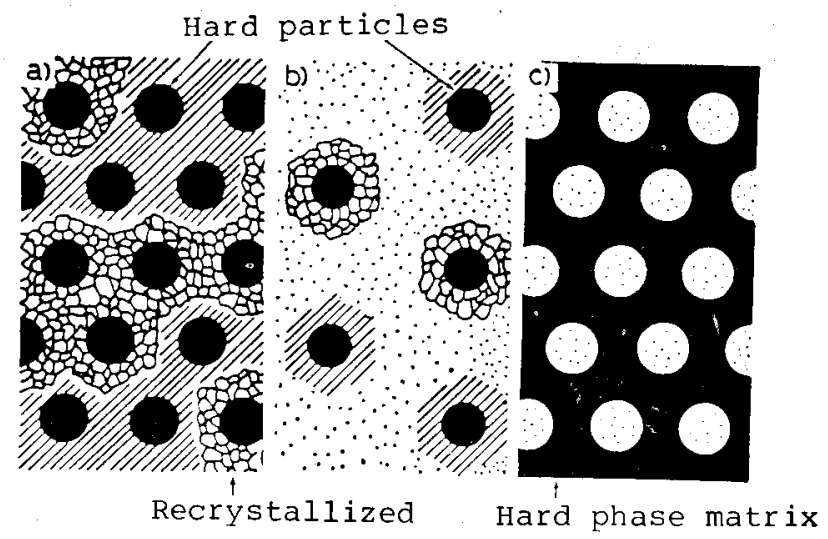

Fig. 9. Maehara's illustration of development of superplastic structure by dynamic recrystallization due to presence of a large amount of second hard phase (left diagram).

The middle diagram illustrates insufficient dynamic recrystallization because of small amount of particles.

The right diagram illustrates inhabitation of dynamic recrystallization due to dispersion of soft particles in hard matrix. containing low-angle grain boundaries in a eutectoid composition steel are not superplastic but can be made superplastic by converting the low angle boundaries to high angle ones by appropriate thermal or thermomechanical treatment. ${ }^{32)}$ Similar results have been obtained in a tool steel. ${ }^{33)}$

\section{(6) Shape of Grains}

The grain shape should be equiaxed in order that the grain boundary can experience a shear stress allowing G.B.S. to occur. Materials with elongated cylindrical grains, even though fine grained in a transverse direction, would not be expected to exhibit very much grain boundary sliding when tested longitudinally. Testing in a transverse direction, however, could lead to extensive grain boundary sliding and therefore result in superplastic behavior.

\section{(7) Mobility of Grain Boundaries}

Grain boundaries in superplastic alloys should be mobile. During grain boundary sliding, stress concentrations develop at triple points, as well as at other obstructions along the grain boundary. The ability of grain boundaries to migrate during grain boundary sliding permits reduction of these stress concentrations. In this manner, grain boundary sliding can continue as the major deformation process. The fact that grains remain equiaxed after extensive superplastic deformation is indirect evidence that grain boundary migration is occurring. One possible explanation to the limited ductility observed in most fine grained ceramic polycrystals at high temperatures (even though the strain-rate-sensitivity exponent is high) is that the grain boundaries are not very mobile. In this case, the lack of boundary mobility can lead to high stress concentrations at triple points during grain boundary sliding, leading to crack nucleation and early failure.

(8) Grain Boundaries and their Resistance to Tensile Separation

Grain boundaries in the matrix phase should not be prone to ready tensile separation. It is generally believed that the grain boundaries in ceramic materials have a high surface energy, and as a result will separate under low tensile stresses. ${ }^{34)}$ This may be the major reason why many fine grained ceramic polycrystals exhibit low ductility in tension even when the strain-rate-sensitivity exponent is high. Perhaps the great success achieved by Wakai et al. ${ }^{26)}$ in making polycrystalline zirconia superplastic is due to the development of extraordinarily fine grains $(d=0.3$ $\mu \mathrm{m}$ ) which reduced the stress required for plastic flow to a value below the boundary tensile fracture stress.

\subsubsection{Optimizing the Rate of Superplastic Flow in FSS Materials}

For a given superplastic material, and at a given temperature, there is a maximum strain rate where superplastic flow by grain-boundary sliding is no longer the dominant process; another mode of deformation becomes important, namely diffusion-controlled dislocation creep (slip creep). The maximum strain rate at which grain boundary sliding remains 
rate-controlling is typically on the order of $10^{-4} \mathrm{~s}^{-1}$, a rate considerably lower than those used in most commercial forming operations (e.g., $10^{-1}$ to $1 \mathrm{~s}^{-1}$ ). From a technological viewpoint it would be desirable to increase the maximum strain rate for superplastic flow. The approach for attainment of this goal is, in principle, straight forward. One must select structural variables that will enhance grain boundary sliding but make slip creep more difficult. We illustrate this schematically in Fig. 10. In this graph, the logarithm of the strain rate is plotted against the logarithm of the flow stress. The two separate processes contributing to grain-boundary sliding and to slip creep are represented as straight lines. The point of intersection (marked 1 ) represents the maximum strain rate for superplastic flow for a given set of microstructural conditions. The dashed lines in the figure indicate how a new set of microstructural conditions can increase the maximum strain rate for superplastic flow by making grain-boundary sliding more facile and by inhibiting the slip creep process. Such a change then leads to an increase in the maximum rate for superplastic flow, as indicated by symbol 2 in Fig. 10. The most evident structural feature that can be utilized to achieve this enhancement in superplasticity is to decrease the grain size. When the grain size is reduced, the superplastic flow rate (by grain boundary sliding) is increased and the normal flow rate (by slip) is reduced (the Hall-Petch relation).

A number of recent investigations have centered

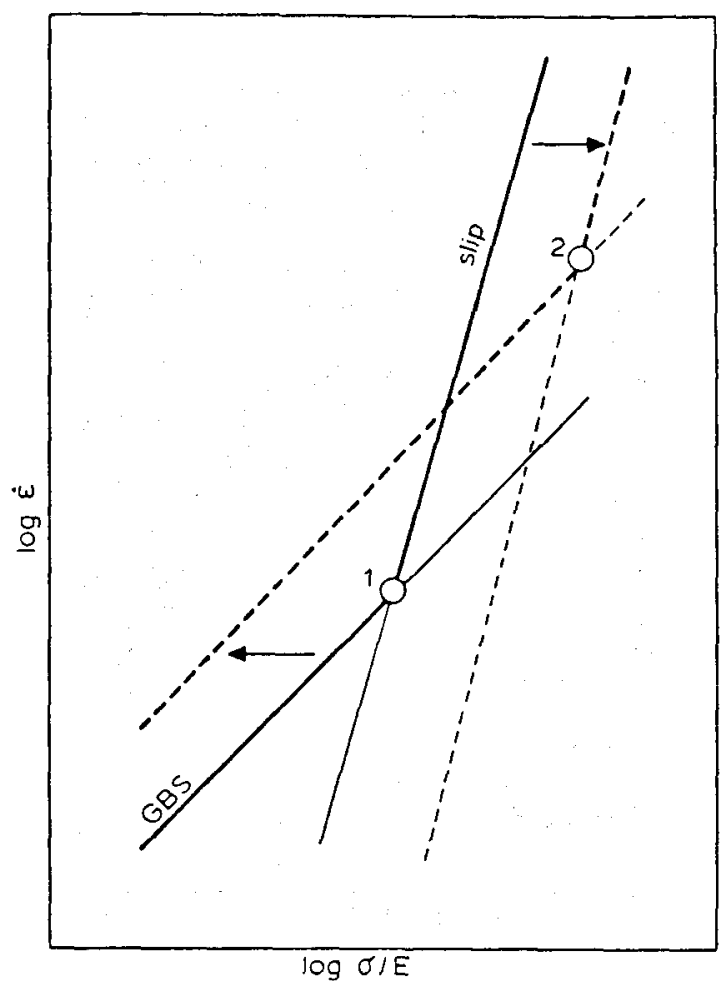

Fig. 10. The solid lines depict the creep rate of a fine-structure superplastic material as a function of stress at a given structural state. If the structural state is changed such that G.B.S is enhanced and slip is made more difficult, as shown by the dashed lines, then the maximum strain rate for superplastic flow is increased (Point 2). on aluminum alloys with the objective of increasing the strain rate range for superplastic flow by grain size refinement. These studies have shed some new insight into understanding the general behavior of superplastic materials and are discussed in the following subsections.

\section{(1) Whisker-reinforced and Mechanically Alloyed} Aluminum

Wadsworth and his colleagues ${ }^{35-38)}$ have made considerable progress in achieving high elongations under high strain rate conditions. They have achieved this success by grain size refinement in whisker reinforced aluminum alloys and in mechanically alloyed aluminum alloys. In one example, ${ }^{35)}$ a composite of Al-2124 containing $20 \mathrm{vol} \% \mathrm{SiC}$ whiskers behaved in a superplastic-like manner (up to $300 \%$ elongation) at the high strain rate of $3 \times 10^{-1} \mathrm{~s}^{-1}$. In another example, ${ }^{36,37)}$ an ultrafine grained, mechanically alloyed Al-9021 (4.2\% Cu-2.0\% Mg-1.1\%C-0.8\%O), exhibited maximum elongations at strain rates as high as $20 \mathrm{~s}^{-1}$. In yet another investigation, ${ }^{38)}$ on a similar mechanically alloyed aluminum alloy, MA-Al IN 90211 , an optimum elongation of $500 \%$ was found at a strain rate of $2.5 \mathrm{~s}^{-1}$.

An overview of the superplastic behavior of the alloys described above is given in Fig. 11 in which elongation to failure is plotted as a function of strain rate. The grain sizes for each class of alloy groups is indicated on the figure. Included in the figure are data for mechanically alloyed nickel-base alloys (MA 754 and IN 6000) by Gregory et al.$^{39)}$ who noted high ductility at high strain rates in these fine grained materials. Wadsworth and his colleagues are currently investigating the precise, operative, deformation mechanisms in these alloys. The observation of superplastic-like behavior ( $m$ is slightly below the typical value of 0.5 ) at such high strain rates, however, is believed to be consistent with the extremely fine (submicron) grain size contained in these complex aluminum composites and alloys.

\section{(2) Al-Mg Base Alloys}

Recently, considerable effort has been devoted to superplasticity studies in $\mathrm{Al}-\mathrm{Mg}$ alloys. Magnesium forms a solid solution in aluminum and up to $10 \%$ magnesium can be dissolved at high temperatures. $\mathrm{Al}-\mathrm{Mg}$ solid solution alloys are known as Class I solid solutions exhibiting high strain rate sensitivity even when coarse grained. ${ }^{40)}$ In these solid solution alloys, the stress exponent is three, that is, $m$ is equal to 0.33 and elongations in the order of about $200 \%$ are often achieved. Class I solid solution alloys are sometimes considered to be superplastic although it is generally agreed that superplastic behavior is not achieved until strain-rate-sensitivity exponents nearly equal to or exceeding 0.5 are obtained. In the following, three separate studies on fine-grained $\mathrm{Al}-\mathrm{Mg}$ alloys are described.

Watanabe et al. ${ }^{(1)}$ have modified an existing commercial $\mathrm{Al}-\mathrm{Mg}$ alloy (AA 5083) by the addition of copper to make it superplastic. The alloy composition of AA 5083 is nominally $5 \% \mathrm{Mg}, 0.7 \% \mathrm{Mn}$, 


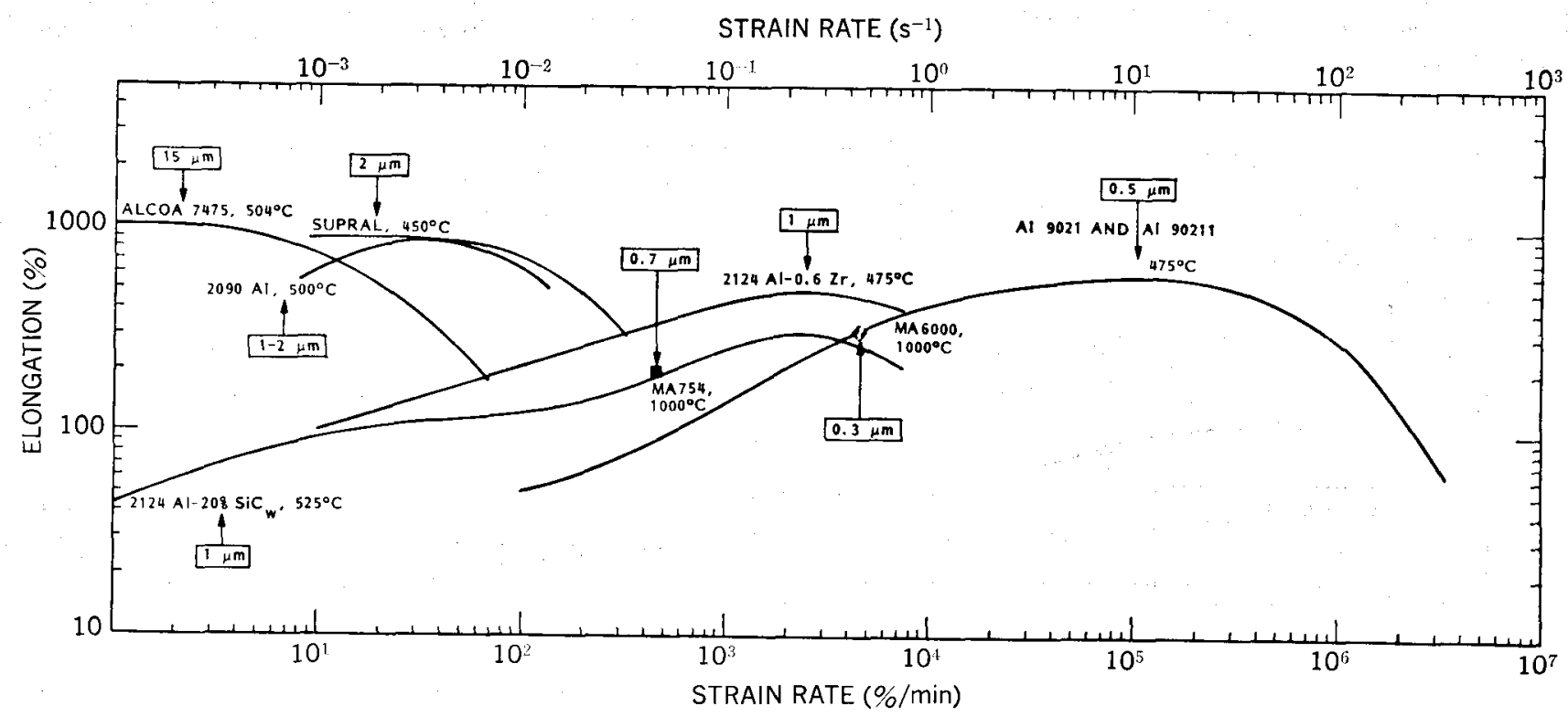

Fig. 11. Overview of superplastic behavior as a function of strain rate for a range of aluminum based materials of grain sizes from $15 \mu \mathrm{m}$ to submicron. Also included are two data points for fine-grained nickel-based superalloys.

$0.12 \% \mathrm{Fe}, 0.13 \% \mathrm{Cr}$ and $0.10 \% \mathrm{Si}$. They showed that, with progressive addition of copper $(0.2,0.4$ and $0.6 \% \mathrm{Cu}$ ) the grain size was increasingly refined after hot and cold rolling, followed by a recrystallization treatment. The grain size of the $0.6 \% \mathrm{Cu}$ alloy was less than $10 \mu \mathrm{m}$. Fig. 12 illustrates the improvement in the ductility with increase in copper content. An elongation of $700 \%$ was obtained at a strain rate of $2.8 \times 10^{-3} \mathrm{~s}^{-1}$ at $550^{\circ} \mathrm{C}$, with a strain rate sensitivity exponent of 0.7 for the AA $5083-0.6 \% \mathrm{Cu}$ alloy. Typical mechanical properties at room temperature of superplastically formed parts from the new alloy are $334 \mathrm{MPa}$ tensile strength and $25 \%$ elongation. These values are superior to those obtained in Supral alloy containing $5 \% \mathrm{Cu}-0.5 \% \mathrm{Zr}$ in the superplastic condition (UTS-181 MPa, $7 \%$ elongation). The newly developed Japanese sheet has the trade name of NEOPRAL and is used for building and construction applications, mostly for decorative components.

Salama and $\mathrm{McNelley}^{42}$ ) have been studying the properties of an $\mathrm{Al}-10 \% \mathrm{Mg}$ alloy containing small additions of either zirconium $(0.2 \%)$ or manganese $(0.5 \%)$. These authors show that, when fine-grained, these alloys are superplastic at relatively low temperatures $\left(300^{\circ} \mathrm{C}\right)$ in contrast to other superplastic aluminum alloys where superplasticity is only observed at high temperatures $\left(475\right.$ to $550^{\circ} \mathrm{C}$ ). In addition, the room temperature strength of the $\mathrm{Al}-10 \mathrm{Mg}$ alloys is superior to other $\mathrm{Al}-\mathrm{Mg}$ alloys because of increased solid solution strengthening. Both alloys studied by Salama and McNelley behaved in a similar manner. Fig. 13 compares the ductility characteristics and stress-strain rate relations of a fine and coarse grained $\mathrm{Al}-10 \mathrm{Mg}-0.1 \mathrm{Zr}$ alloy at $300^{\circ} \mathrm{C}$. As can be seen, the coarse grained alloy $(d=40 \mu \mathrm{m})$ exhibits a maximum $m$ value of 0.33 with maximum elongations in the order of $200 \%$. On the other hand, the fine grained alloy $(d=3 \mu \mathrm{m})$ exhibits $m$ values approaching 0.5 with a maximum elongation of $500 \%$.

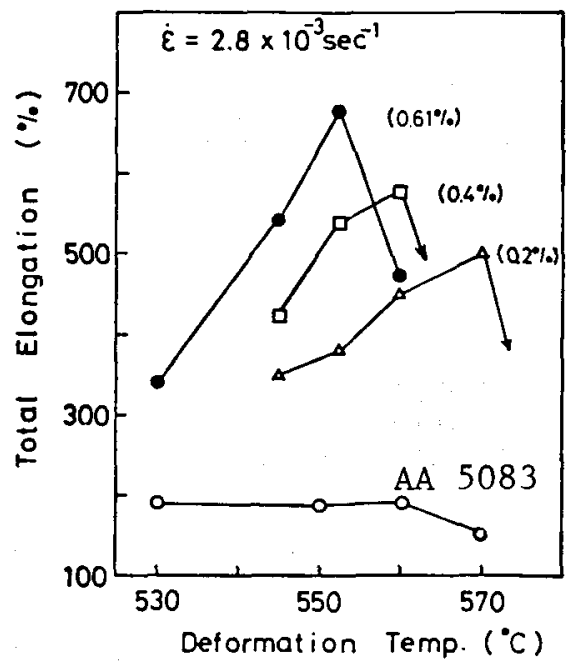

Fig. 12. Influence of copper additions on the tensile ductility of a fine-grained Al-5Mg alloy (AA 5083). Data from Watanabe, Ohori and Takeuchi.

Fig. 14 compares the creep rate-stress relation of the coarse-grained $\mathrm{Al}-10 \mathrm{Mg}-0.1 \mathrm{Zr}$ alloy with the typical behavior observed in Class I dilute $\mathrm{Al}-\mathrm{Mg}$ solid solution alloys. The data are plotted as diffusion-compensated creep rate as a function of moduluscompensated stress. The creep relation for pure aluminum is shown for comparison. The creep data for the coarse-grained $\mathrm{Al}-10 \mathrm{Mg}-0.1 \mathrm{Zr}$ alloy is seen to superimpose on the dashed line representing the behavior of dilute $\mathrm{Al}-\mathrm{Mg}$ alloys where solute-drag-controlled dislocation creep is well established as the rate-controlling process. In contrast, a fine-grained $\mathrm{Al}-10 \mathrm{Mg}-0.52 \mathrm{Mn}$ alloy $(d=8 \mu \mathrm{m})$ is plotted in the same manner in Fig. 15. In this case, the creep rates are seen to exceed those predicted by solute-dragcontrolled dislocation creep. This is because grain boundary sliding is contributing significantly to the deformation process. An additional trend can also be 


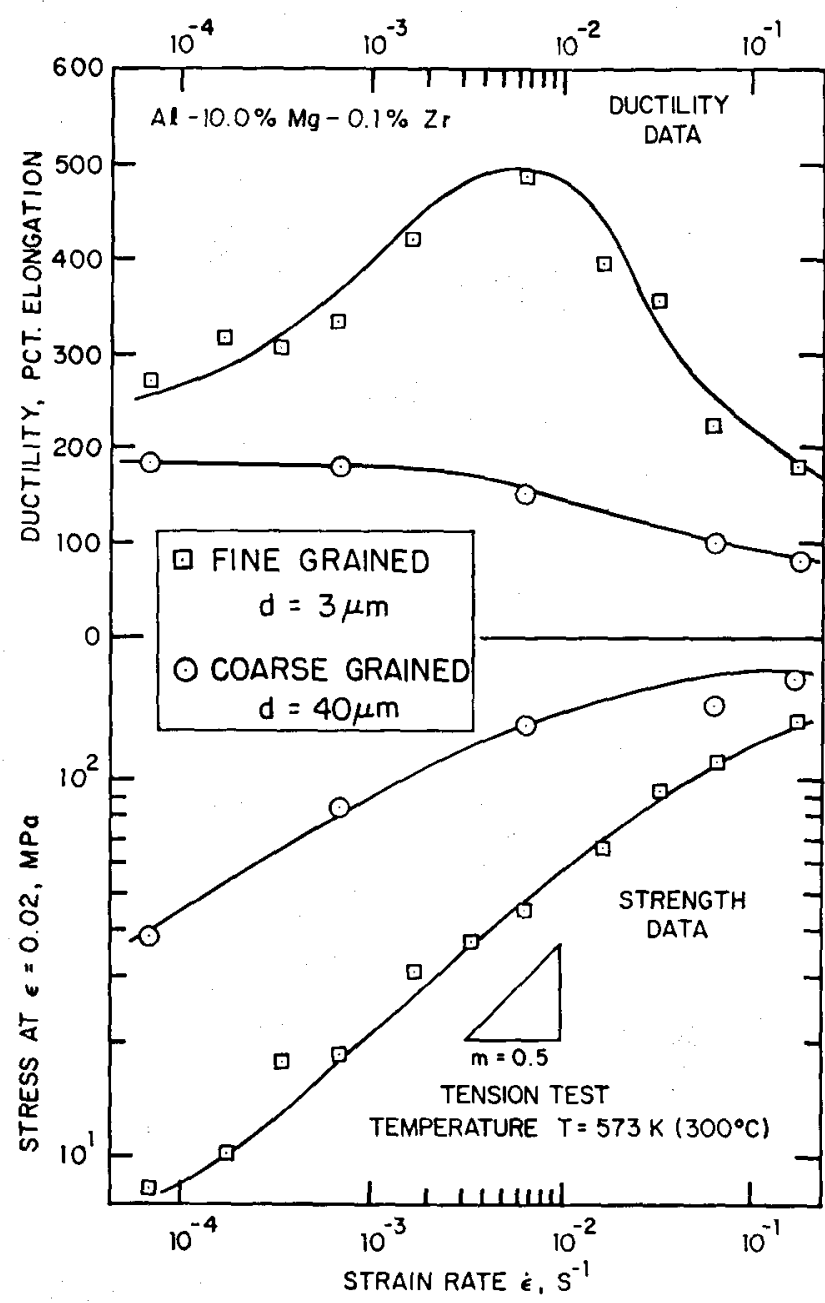

Fig. 13. Comparison of the ductility and flow stress-strain rate behavior of a fine and coarse grained $\mathrm{AI}-$ $10 \mathrm{Mg}-0.1 \mathrm{Zr}$ at $300^{\circ} \mathrm{C}$.

Data from Salama and McNelley. noted. At low strain rates for each temperature the stress exponent is seen to increase. This trend can be viewed as the initiation of Stage I deformation extensively discussed in the literature for superplastic materials. ${ }^{43)}$ There is evidence to suggest that this behavior is due to the presence of a threshold stress for grain boundary sliding which is temperature dependent. This point will be discussed in the next paragraph.

The superplastic properties of a P.M. product based on $\mathrm{Al}-5 \mathrm{Mg}-1.2 \mathrm{Cr}$ has been studied by Shin et al. ${ }^{44)}$ After consolidation of the powders by hot compaction, followed by thermal-mechanical processing, a fine-grained $(d=2 \mu \mathrm{m})$ condition was achicved. The material exhibited high elongations $(\geq 1000 \%$ ) at high strain rates $\left(\dot{\varepsilon}=2 \times 10^{-2} \mathrm{~s}^{-1}\right)$ when tested at high temperature $\left(550^{\circ} \mathrm{C}\right)$. The creep behavior was similar to those observed by Salama and McNelley and the results are shown in Fig. 16. At intermediate strain rates, the fine-grained material exhibits a stress exponent of about two or less $(m=\geq 0.5)$. At low strain rates, the stress exponent increases, and this increase occurs at lower stresses as the temperature of testing is increased. A very significant observation is that the high stress exponent appears to decrease again at very low strain rates as the base-line for solutedrag-controlled dislocation creep is reached.

The trends shown in Fig. 16 suggest that there are two competing independent processes during deformation of fine-grained superplastic materials. These processes are grain boundary sliding with a threshold stress and dislocation-controlled slip. This concept is schematically illustrated in Fig. 17. The dash-dot line in the figure depicts the creep rate of a finegrained material when grain boundary sliding with a threshold stress is the deformation process. The

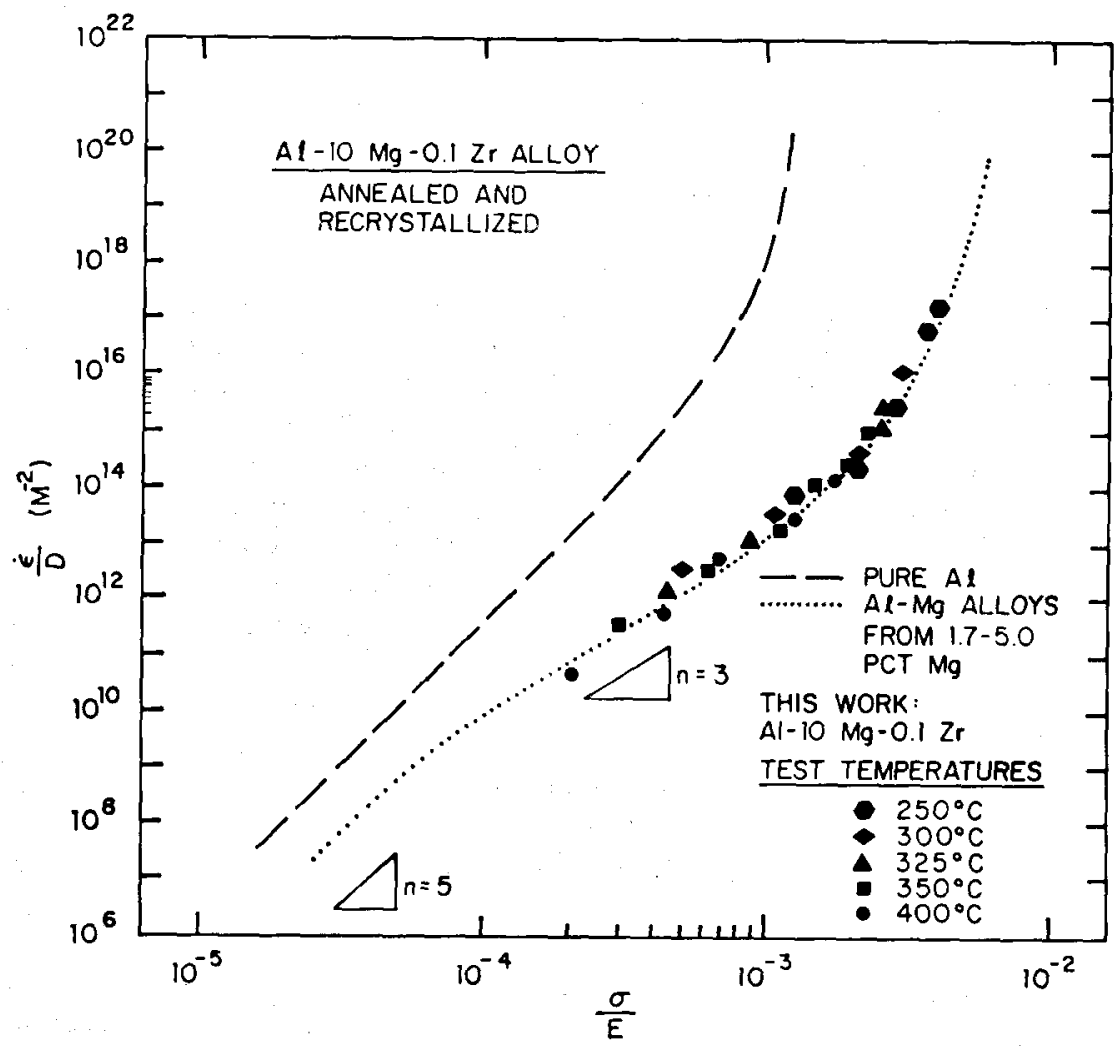

Fig. 14.

Diffusion-compensated strain rate vs. modulus-compensated stress for the coarse-grained (d $\sim 40 \mu \mathrm{m}) \quad \mathrm{Al}-10 \mathrm{Mg}-0.1 \mathrm{Zr}$ alloy. The data fall on the curve for creep of Class $I$ solid solution $\mathrm{Al}-\mathrm{Mg}$ alloys. Data from Salama and McNelley. 


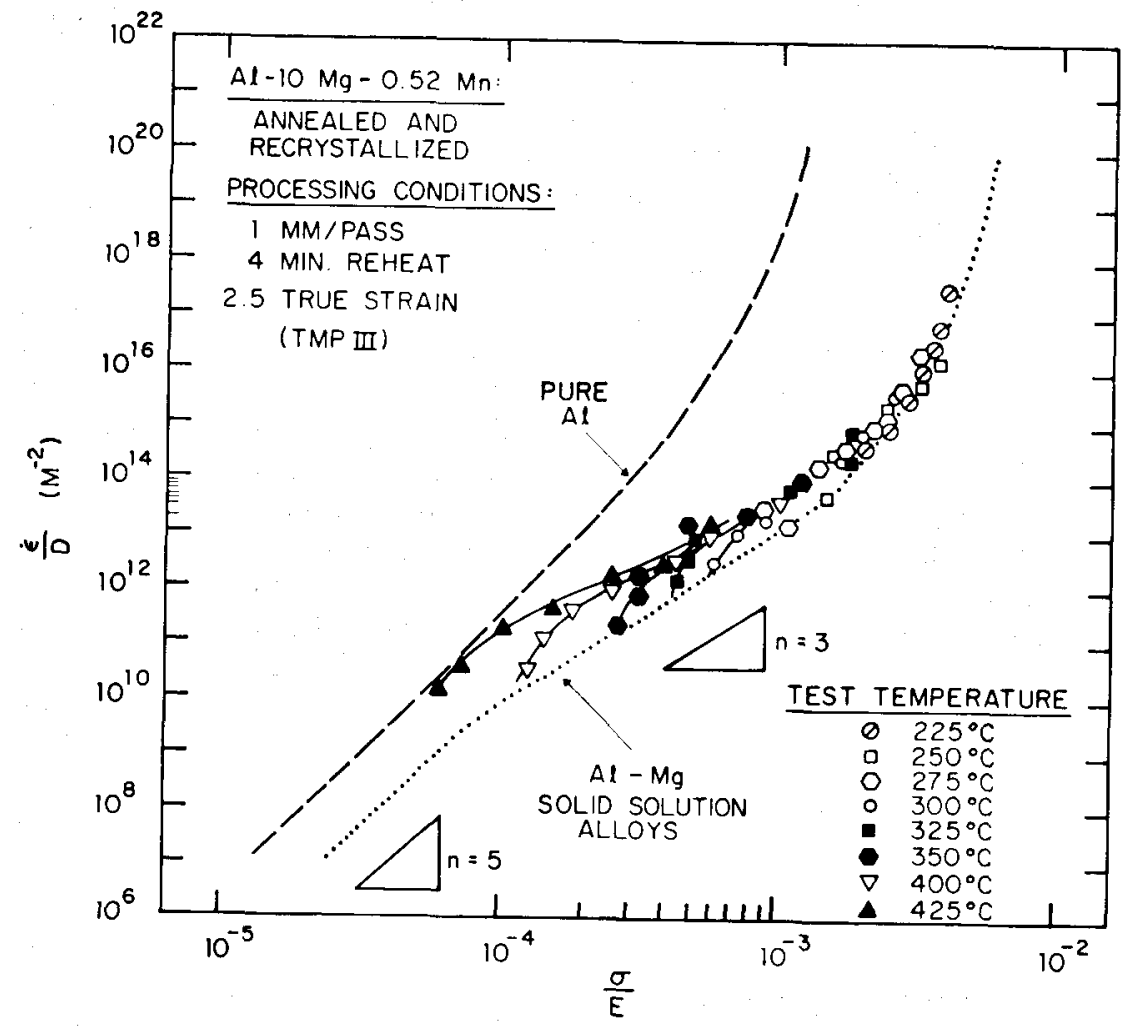

Fig. 15. Diffusion-compensated strain rate vs. modulus-compensated stress for a fine-grained $\mathrm{Al}-10 \mathrm{Mg}-0.52 \mathrm{Mn}$ alloy $(d \sim 8 \mu \mathrm{m})$ tested at temperatures from 225 to $425^{\circ} \mathrm{C}$. Superplastic behavior is observed at temperatures above $350^{\circ} \mathrm{C}$.

Data from Salama and McNelley.

dashed line in the figure represents the creep rate of the material when dislocation creep in the matrix is the rate-controlling process. Since these two processes are considered to be independent processes, the fastest of the two processes is rate-controlling. The predicted behavior is given by the shaded curve. Four ranges are depicted: Ranges 0, I, II, III. Ranges 0 and III represent deformation controlled by slip and Range II is where superplastic flow is expected. Range III is where a threshold stress is observed and where low ductility can be expected. The data in Figs. 15 and 16 indicate that the threshold stress is a function of temperature, decreasing in magnitude with increase in temperature. The actual meaning of threshold stress and its value as a function of temperature, as well as of grain size, is not clear and is an area of investigation worthy of considerable additional studies.

\subsubsection{Mechanisms of Deformation in FSS Materials}

It would appear that the structural prerequisites for fine structure superplasticity are quite well developed, and many new alloys have been developed in recent years with the specific objective of achieving superplastic characteristics. A detailed understanding of the exact mechanism of plastic flow in FSS materials, however, has not been as thoroughly developed. The most commonly considered mechanism involves grain boundary sliding. It is generally thought that an accommodation process accompanies

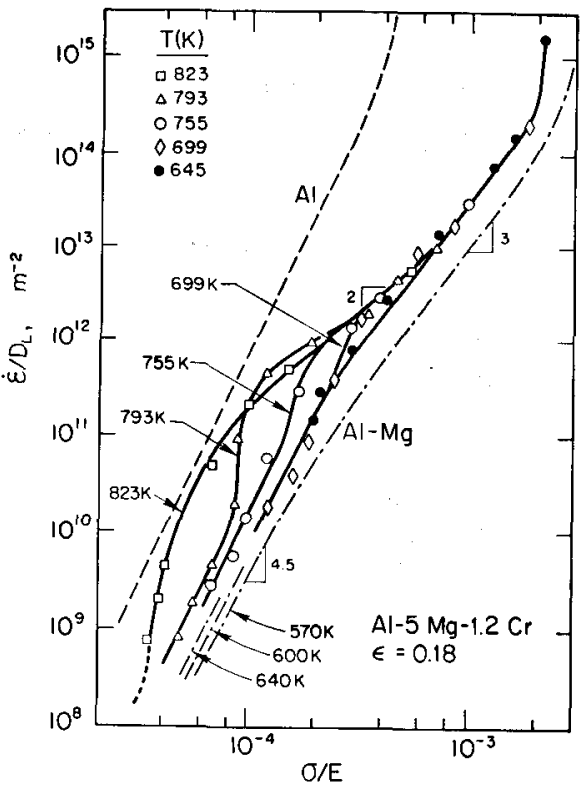

Fig. 16. Diffusion-compensated strain rate vs. modulus-compensated stress for a PM processed $\mathrm{Al}-5 \mathrm{Mg}-1.5 \mathrm{Cr}$ alloy $(d \sim 2 \mu \mathrm{m})$. High strain rate sensitivity is observed at intermediate stresses followed by a threshold stress region with decreasing stress. The threshold stress is a function of temperature.

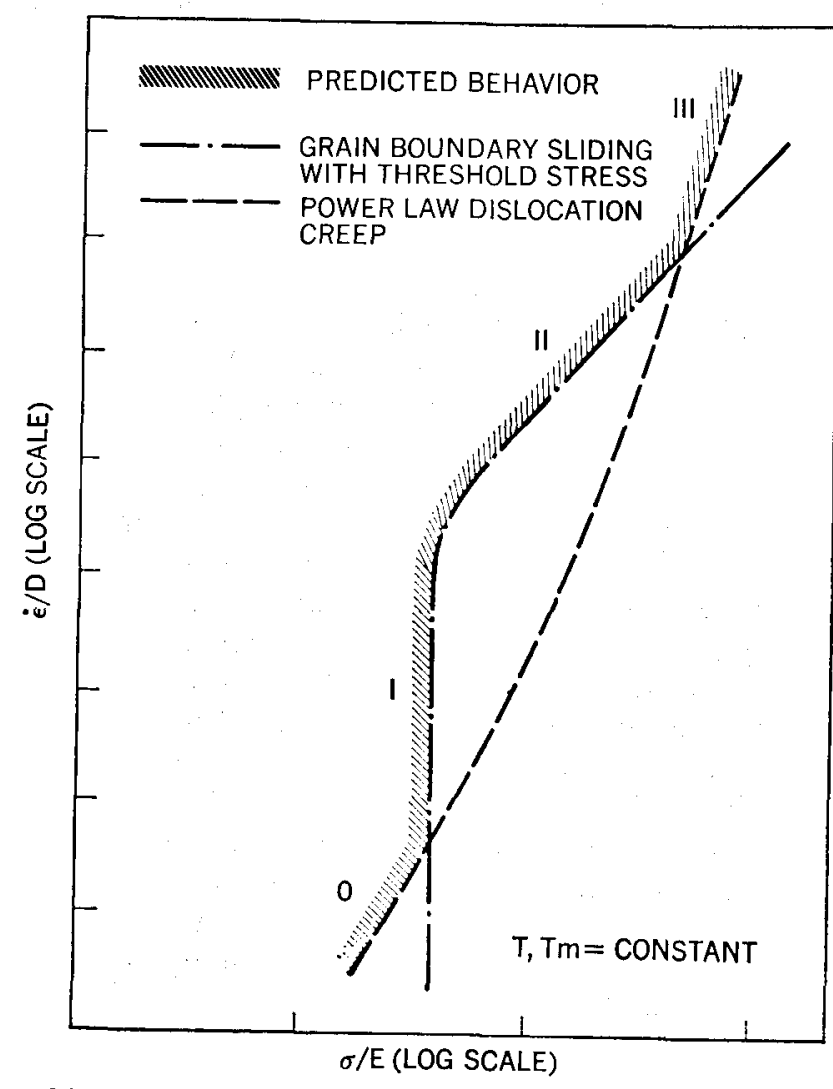

Fig. 17. Prediction of the creep behavior of a fine-grained material based on two independent processes: grain boundary sliding with a threshold stress and slip (power-law dislocation creep). Four ranges are depicted by 0, I, II and III. 
grain boundary sliding. This accommodation process might be grain boundary migration, recrystallization, diffusional flow or some dislocation slip process. Quantitative models have been developed to describe superplastic flow accommodated by slip recovery processes. Examples are those given by Ball and Hutchinson, ${ }^{45)}$ by Mukherjee, ${ }^{46)}$ and by Langdon. ${ }^{47)}$ The "core and mantle" theory of Gifkins"s) also considers slip recovery mechanisms in the vicinity of the grain boundary. A different view is that of grain boundary sliding accommodated by diffusional flow, and such a model has been quantitatively developed by Ashby and Verrall.49) All these models have some features which are in agreement with experimental observations in superplastic materials. These models, however, have not been able to predict quantitatively the creep rates actually observed in fine-grained superplastic materials. In addition, none of the theories are able to predict, in one relation, the correct stress, temperature and grain size dependencies. ${ }^{23}$

Another obstacle to understanding mechanisms of superplastic flow is the existence of Range I creep (described earlier in association with Figs. 15 to 17). Whereas many researchers associate this low stress region with low strain-rate sensitivity, others have observed high strain-rate sensitivity in this region even in the same alloy system, and some fierce debates have come about on this subject. ${ }^{50,51)}$ Range I creep has been explained and discussed in various ways: for example, as a new deformation process controlled by slip, ${ }^{52)}$ as a process associated with a threshold stress for plastic flow, and as a grain boundary sliding process with a reduced creep rate from grain growth. ${ }^{53)}$ Another view, developed by Mayo, ${ }^{54)}$ utilizes a modification of Gifkins" "core and mantle" model to explain Ranges I to III in the following way. The core is assumed to have a typical strain rate sensitivity exponent as is observed in coarse grained materials (i.e., $m=0.2$ ). The mantle region is considered to be weaker than the core region but otherwise has a similar strain-rate-sensitivity exponent. Mayo assumes that the mantle region, which has a finite wide, increases in volume with a decrease in stress, and it is this change with stress that leads to the transition Range II. Such a model allows for obtaining values of $m$ higher than 0.2 although a specific value of $m$ is not predicted for Range II. Experimental work by Mayo on surface observations of grains in the superplastic region (involving $\mathrm{Pb}-\mathrm{Sn}$ and $\mathrm{Zn}-\mathrm{Al}$ alloys) suggests that the mantle region makes up a large fraction of the total material.

Typical strain-rate-sensitivity exponents observed in FSS materials are values clustered around 0.5 . This is especially true at intermediate temperatures and at fine grain sizes where the activation energy for superplastic flow is equal to that for grain boundary diffusion. ${ }^{2)}$ At high temperatures, however, where the activation energy for superplastic flow is equal to that for lattice diffusion, the strain-rate-sensitivity exponent is equal either to 0.5 or to values greater than 0.5.2) Fukuyo et al.55) have recently developed a model to explain the different results obtained at high temperatures. The model is similar to the BallHutchinson, Mukherjee, Langdon concept based on a grain boundary sliding process accommodated by slip. Fig. 18 illustrates the model. As can be seen, the slip accommodation process involves the sequential step of glide and climb. When climb is the rate controlling step, the strain-rate-sensitivity exponent is 0.5 due to the pile-up stress at the head of the climbing dislocation (this, in fact, is the prediction of the Ball-Hutchinson, Mukherjee, Langdon relations). When glide is the rate-controlling step, however, the strain-rate-sensitivity exponent is equal to unity because there is no pile-up stress. Since glide and climb processes are sequential, the slowest of the two processes is rate controlling. This model predicts that fine-grained Class I solid solution alloys can exhibit high values of $m$ since in these alloys the glide step (solute-drag controlled dislocation creep) is often the slowest process. ${ }^{40,56)}$ On the other hand, finegrained Class II solid solution alloys, where dislocation climb is the rate-controlling step, should exhibit $m$ values equal to 0.5 .

The predictions of Fukuyo et al., ${ }^{55)}$ have been confirmed for a number of fine-grained solid solution alloy systems studied at high temperatures, as can be seen in Figs. 19 and 20. These figures illustrate a plot of the strain-rate-sensitivity exponent as a function of the strain rate for fine-grained Class I solid solution alloys (Fig. 19) and for fine-grained Class II solid solution alloys (Fig. 20). The strain rate is normalized to the strain rate where the strain-ratesensitivity exponent, $m$, is equal to 0.3 . In this manner, the different materials can be assessed from a common base. The Class I solid solution alloys shown in Fig. 19 are $\mathrm{Fe}-10 \mathrm{Al}-1.25 \mathrm{C},{ }^{55)} \mathrm{Ti}-6 \mathrm{Al}-$

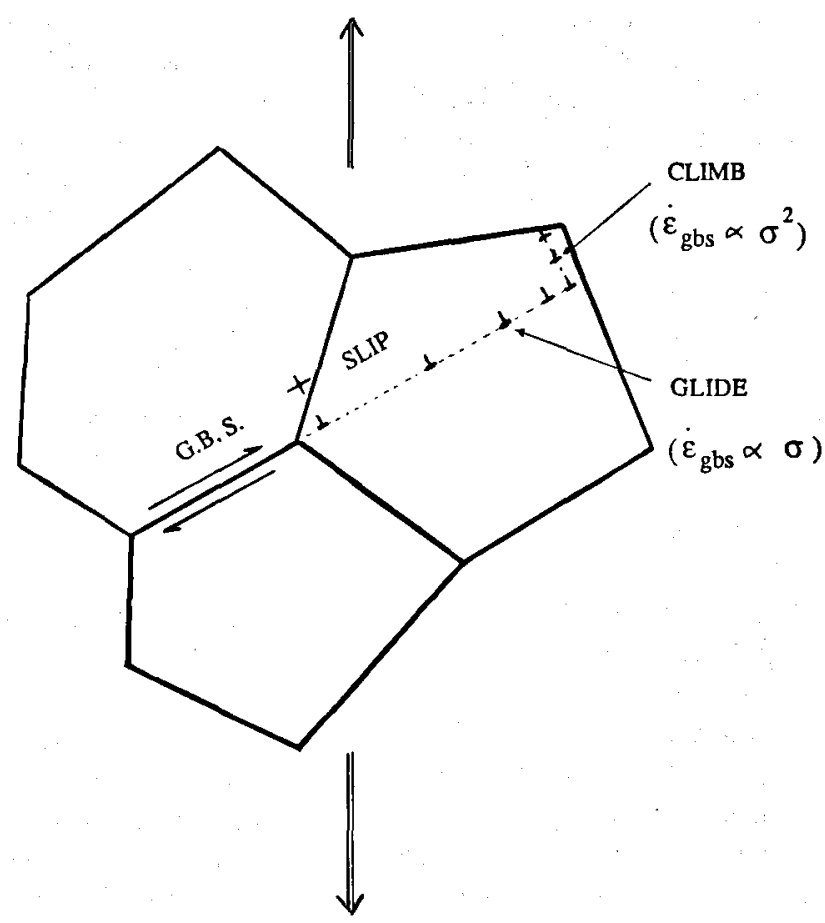

Fig. 18. Model illustrating grain boundary sliding accommodated by dislocation motion involving the sequential steps of glide and climb. 


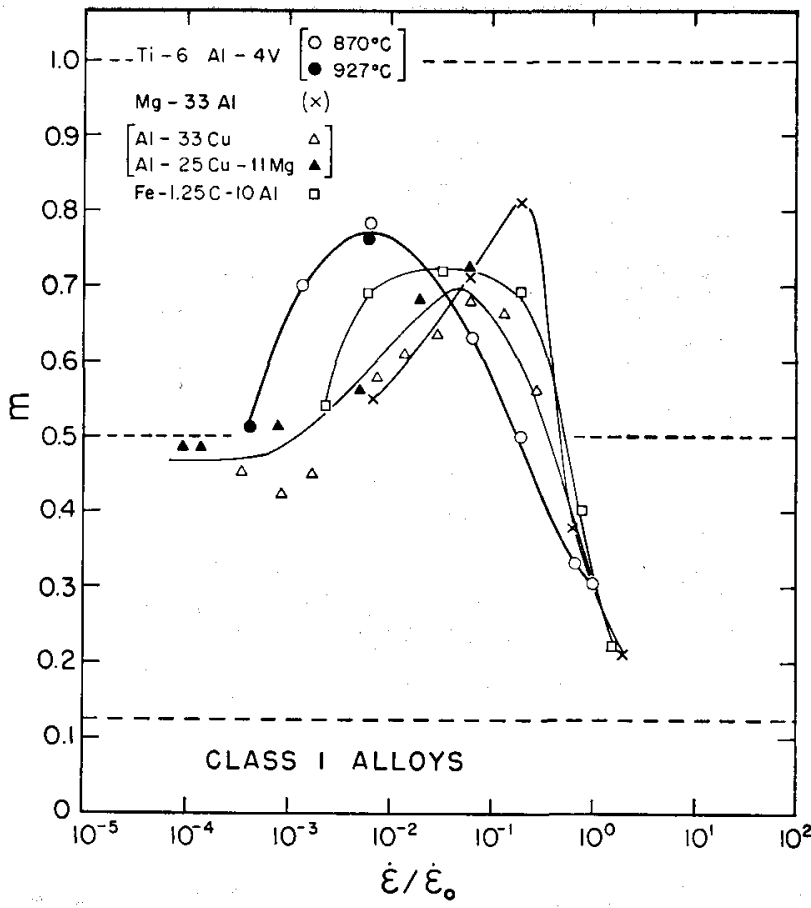

Fig. 19. Influence of normalized strain rate on the strainrate-sensitivity exponent, $m$, for superplastic materials considered as fine-grained Giass I solid solution alloys.

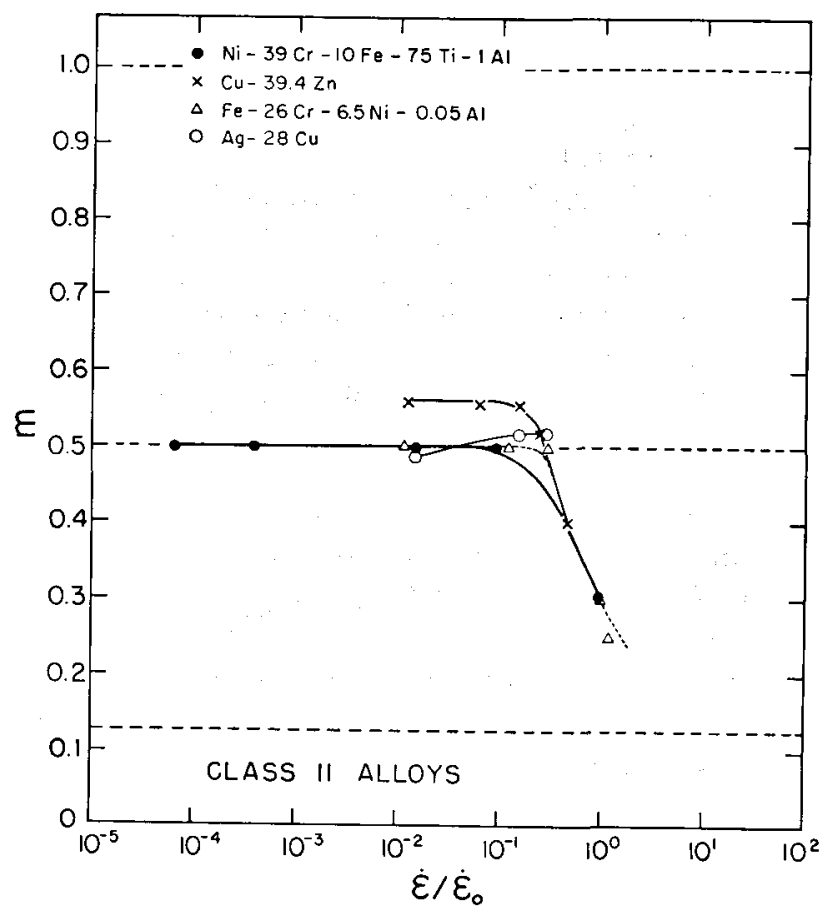

Fig. 20. Influence of normalized strain rate on the strainrate-sensitivity exponent, $m$, for superplastic materials considered as fine-grained Class II solid solution alloys.

$4 \mathrm{~V},{ }^{57,58)} \mathrm{Mg}-33 \mathrm{Al},{ }^{59)} \mathrm{Al}-33 \mathrm{Cu}^{60)}$ and $\mathrm{Al}-25 \mathrm{Cu}-$ $11 \mathrm{Mg}{ }^{61)}$ The strain-rate-sensitivity exponent is about 0.5 at low strain rates, then increases with increasing strain rate to values as high as 0.8 . This is the trend predicted from the Fukuyo et al. ${ }^{55)}$ model wherein at low strain rates, the grain boundary sliding process is accommodated by climb, whereas at high strain rates it is accommodated by glide. These two regions are to be identified as part of Range II of Fig. 17. At yet higher strain rates, slip deformation becomes the dominant deformation mode and the $m$ value decreases to low values in the order of 0.1 to 0.2 . The superplastic materials shown in Fig. 20 exhibit trends that are quite different from those observed for the fine-grained Class I solid solution alloys. The four alloys listed are: $\mathrm{Ni}-39 \mathrm{Cr}-10 \mathrm{Fe}-7.5 \mathrm{Ti}-1 \mathrm{Al},{ }^{62)} \mathrm{Cu}-$ $39.4 \mathrm{Zn},{ }^{63)} \mathrm{Fe}-26 \mathrm{Cr}-6.5 \mathrm{Ni}-0.05 \mathrm{Al}^{64)}$ and $\mathrm{Ag}-28 \mathrm{Cu} .{ }^{651}$ For these fine-grained solid solution materials, the strain-rate sensitivity exponent is about 0.5 at low strain rates. With increasing strain rates, $m$ decreases. This is the type of creep behavior expected in fine grained Class II solid solution alloys since the accommodation process, in this case, is grain boundary sliding controlled by dislocation climb where $m$ equals 0.5 .

\subsection{Internal Stress Superplasticity (ISS)}

In addition to the fine structure superplasticity described in the previous section, there is another type of superplasticity known as internal stress superplasticity. ${ }^{3)}$ In these materials, in which internal stresses can be developed, considerable tensile plasticity can take place under the application of a low, externallyapplied, stress. This is because internal-stress superplastic materials can have a strain-rate sensitivity exponent of as high as unity, i.e., they can exhibit ideal Newtonian-viscous behavior. Such superplastic materials deform by a slip deformation mechanism.

There are many ways in which internal stresses can be generated. These include thermal cycling of composite materials in which the constituents have different thermal expansivity coefficients, ${ }^{66-71)}$ thermal cycling of polycrystalline pure metals or single phase alloys that have anisotropic thermal expansion coefficients, ${ }^{71,72)}$ and thermal cycling through a phase change. ${ }^{4,73-76)}$

\subsubsection{Whisker and Particle Reinforced Composites}

It has been shown that internal stress superplasticity can be utilized to enhance the ductility of metalmatrix composites that are normally brittle. Thus, a whisker-reinforced metal-matrix composite (Al$20 \% \mathrm{SiC}_{w}$ alloy) was made ideally superplastic, i.e., Newtonian viscous in nature, during deformation under thermal cycling conditions. ${ }^{66-71)}$ An example of the exceptional tensile ductility that can be achieved in this manner, in a whisker-reinforced $6061 \mathrm{Al}$ alloy, is shown in Fig. 21.69) Whereas the metal-matrix composite exhibits only $12 \%$ elongation under isothermal deformation at $450^{\circ} \mathrm{C}$, the same composite exhibits $1400 \%$ elongation if deformed under thermal cycling conditions $\left(100 \leftrightarrow 450^{\circ} \mathrm{C}\right.$ at $100 \mathrm{~s}$ per cycle). An example of similar behavior was demonstrated with a zinc-30vol\% alumina particulate composite. ${ }^{67,68)}$ Whereas this material exhibited essential nil ductility when tested in tension at $300^{\circ} \mathrm{C}$, it exhibited Newtonian-viscous behavior when deformed under thermal cycling conditions, and elongations exceeding $150 \%$ were achieved. 


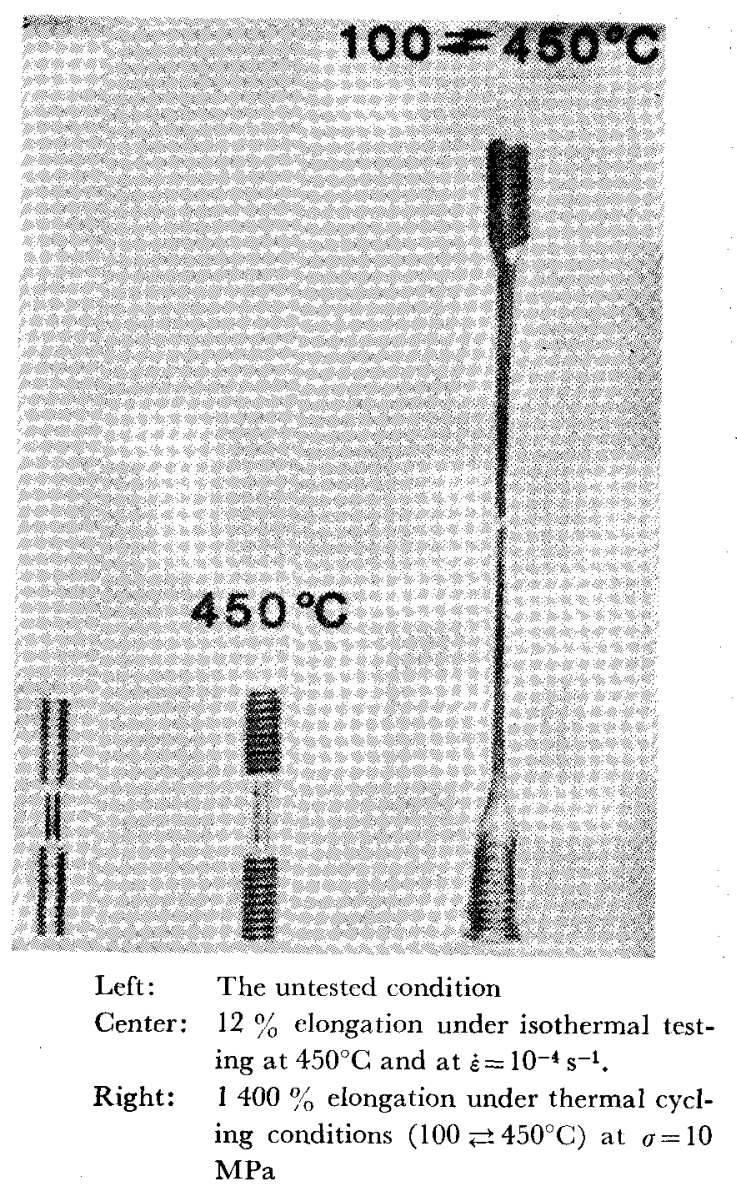

Fig. 21. Tensile ductility of Al-6061-SiC , reinforced composite.

From G. González et al.

The basis of understanding the effect of internal stress on enhancing the ductility of metal-matrix composites is as follows. ${ }^{72}$ During thermal cycling, internal stresses are developed at the interfaces between the metal-matrix and the hard ceramic second phase. This is because the thermal expansion coefficient of the metal-matrix is several times larger than that of the ceramic phase. These internal stresses will relax by plastic deformation in the metal-matrix to the value of the local interfacial yield stress of the material. It is this remaining local yield stress, which we define as the internal stress, $\sigma_{i}$, which contributes to the low applied external stress, and results in macroscopic deformation along the direction of the applied stress. This model is developed quantitatively in the next subsection. The creep behavior of two Al-2024$\mathrm{SiC}_{w}$ composites under both thermal cycling and isothermal conditions are shown in Fig. 22..$^{70}$ The graph shows a plot of the diffusion-compensated creep rate as a function of the modulus-compensated stress. Three trends can be noted. First, the thermally cycled composites are much weaker than the isothermally tested composites at low applied stresses. Second, the thermally cycled composites have strain-ratesensitivity exponents of unity at low stresses. Third, the thermally cycled samples and the isothermally tested samples yield data that converge at high stresses; this is expected since the internal stress gen-

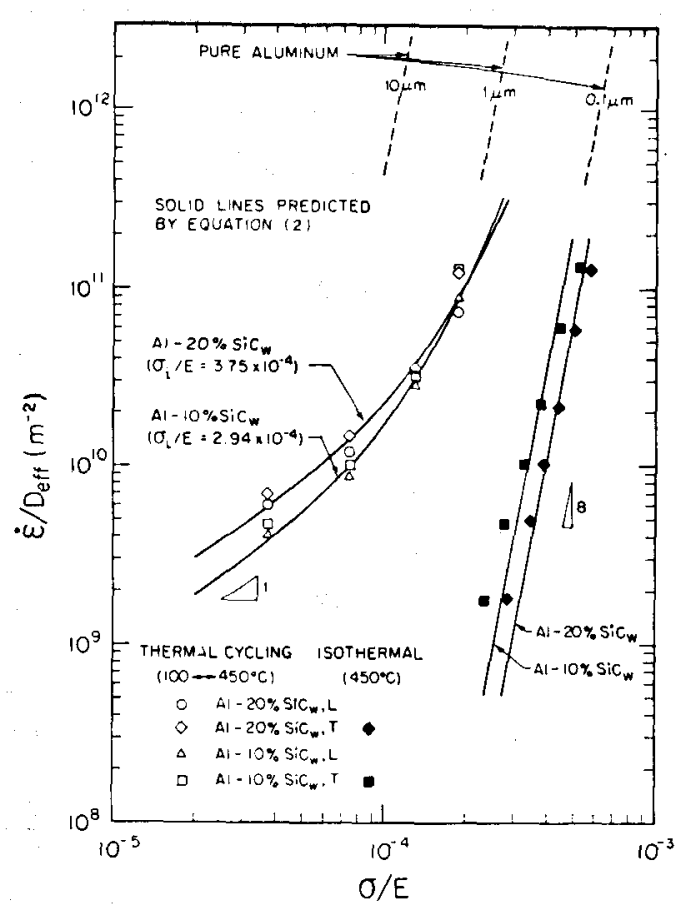

Fig. 22. Diffusion-compensated strain rate as a function of modulus-compensated stress for thermal cycled and isothermal creep data for Al-2024 alloy composite containing $10 \% \mathrm{SiC}_{w}$ and $20 \% \mathrm{SiC}_{w}$. Data from S. Hong $e t$ al.

erated by thermal cycling (a constant) will have a diminishing contribution to creep as the applied stress is increased.

It was observed that the manner in which the silicon carbide whiskers flowed during plastic deformation of the composite was dramatically different under thermal cycling conditions by comparison with isothermal conditions. ${ }^{66,69,70)}$ For example, $\mathrm{Wu}$ and Sherby ${ }^{66)}$ have shown that regions devoid of whiskers in a 2024-20 $\mathrm{vol} \% \mathrm{SiC}_{w}$ extruded composite become readily filled with whiskers when deformed in tension under thermal cycling conditions. An example of the difference in the rate of reorientation of whiskers in the same extruded $202420 \mathrm{vol} \% \mathrm{SiC}_{w}$ composite, when deformed in compression under isothermal and thermal cycling conditions, ${ }^{70}$ is shown in Fig. 23. The sample that was deformed isothermally exhibited very limited reorientation of the whiskers towards the direction of compression flow. Furthermore, extensive surface cracks were observed in the sample. On the other hand, the sample that was deformed under thermal cycling conditions, to the same strain, showed that nearly all whiskers were no longer in the original longitudinal direction. Clearly, Newtonian-viscous flow of the metal-matrix accelerates the reorientation of the $\mathrm{SiG}$ whiskers. No surface cracks were observed in the thermally cycled sample.

\subsubsection{Anisotropic Expanding Polycrystalline Mate- rials}

Other examples of internal stress superplasticity are in polycrystalline zinc and alpha uranium. In the case of these two metals, the internal stress arises from the anisotropy of expansion coefficients present in 

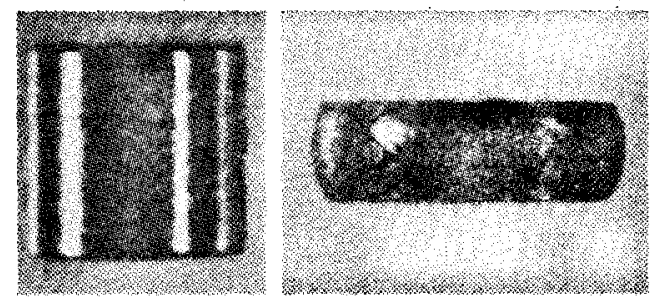

UNDEFORMED

NORMAL PLASTIC FLOW

SAMPLE CONSTANT TEMPERATURE $\left(450^{\circ} \mathrm{C}\right)$
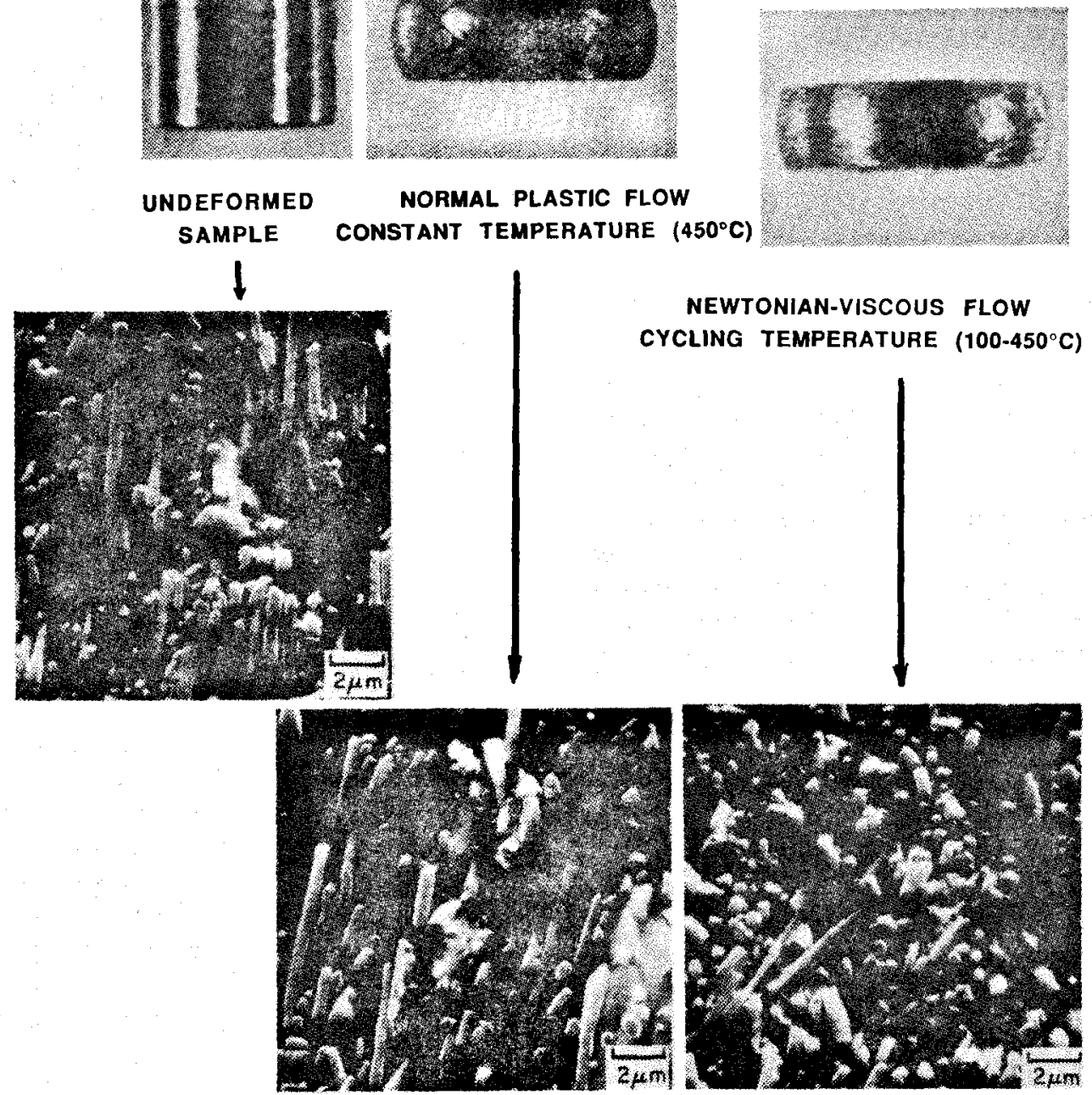

Fig. 23. The above graph illustrates that Newtonian-viscous flow in a whisker reinforced Al-2024-20\% $\mathrm{SiC}_{w}$ composite leads to crack-free plastic flow and to rapid reorientation of whiskers.

these non-cubic structure materials. During thermal cycling internal stresses will be induced at the boundaries between adjacent grains.

A quantitative relation was developed by $\mathrm{Wu}$ et al. to describe the thermal cycling behavior of anisotropic polycrystalline materials and composites. ${ }^{72)}$ The model begins with the Garofalo hyperbolic sine creep relation, ${ }^{77)}$ which describes the steady state creep rate of metals that are controlled by diffusion-assisted dislocation creep. This relation is given as:

$$
\dot{\varepsilon}=\left(K / \alpha^{n}\right) D_{\text {eff }} / b^{2}[\sinh \alpha \sigma / E]^{n}
$$

where, $\alpha, K$ : constants

$b$ : Burgers' vector

$D_{\text {eff }}$ : the effective diffusion coefficient

$E$ : Young's modulus

$n$ : the stress exponent (equal to the reciprocal of the strain-rate-sensitivity exponent)

$\sigma:$ the applied creep stress.

The value of $n$ is typically in the range 5 to 8 .

The theory of Wu et al. ${ }^{72)}$ uses this equation on the assumption that the internal stresses generated during thermal cycling contribute to plastic flow in the following way: at any given time, half of the moving dislocations are aided by the presence of the internal stress, whereas the remaining half of the dislocations are opposed by the presence of the internal stress. The theory also assumes that these two groups of dislocations contribute to plastic flow independently of each other. The following equation results:

$$
\begin{aligned}
\dot{\varepsilon}= & 1 / 2\left(K / \alpha^{n}\right) D_{\text {eff }} / b^{2}\left\{\left[\sinh \alpha\left(\sigma+\sigma_{i}\right) / E\right]^{n}\right. \\
& \left.+\left|\sigma-\sigma_{i}\right| /\left(\sigma-\sigma_{i}\right)\left[\sinh \alpha\left(\sigma-\sigma_{i}\right) / E\right]^{n}\right\}
\end{aligned}
$$

When the applied stress is much greater than the internal stress this expression leads to the Garofalo equation [Eq. (1)]. In this case the prediction is that the material under thermal cycling conditions approaches the isothermal behavior with a high stress exponent preventing attainment of superplastic properties. However, for the low applied stress range, for example on the order of (or lower than) the internal stress present within a material, Eq. (2) reduces to:

$$
\dot{\varepsilon}=K_{n} D_{\mathrm{efr}} / b^{2}\left(\sigma_{i} / E\right)^{n-1} \sigma / E
$$


which is characterized by a stress exponent of $n=1$. This equation predicts that deformation in this range will result in Newtonian-viscous behavior and hence superplasticity is expected in the low applied stress range. This model correctly predicts the Newtonian flow behavior for a number of materials under thermal cycling conditions. ${ }^{67-70,72)}$ It was shown ${ }^{72)}$ that the internal stress term can, in fact, be estimated without recourse to performing thermal-cycling tests. The value of the internal stress is given by

$$
\sigma_{i} / E=\left[2.2 \times 10^{-4} b^{2} / \dot{t} K D\right]^{1 / n}
$$

where $i$ is the cycle rate (s/cycle).

Eqs. (2) and (4) were utilized to predict the thermal cycling behavior of polycrystalline zinc and alpha uranium under different conditions of cycling and temperature ranges. Fig. 24 illustrates the predicted curves with those obtained experimentally. ${ }^{72}$ As can be seen, the thermal cycling data are well predicted by Eq. (2). At low values of the modulus-compensated stress, the model predicts, and the data demonstrate, the existence of ideal Newtonian-viscous flow $(m=1)$; under these experimental conditions, superplastic behavior is indeed observed. ${ }^{71,72)}$

The thermal cycling data shown for the $2024-\mathrm{SiC}_{z}$ composite in Fig. 22 was also predicted from equation (2). As can be seen, the predicted curves fit very well with the experimental points.

\subsubsection{Materials Undergoing Polymorphic Changes}

Materials that undergo polymorphic changes with temperature can exhibit Newtonian-viscous behavior when tested under thermal cycling conditions. Among the early investigations on this subject were those of Sauveur, ${ }^{73)}$ Wasserman, ${ }^{78}$ de Jong and Rathenau, ${ }^{74}$ and Clinard and Sherby ${ }^{75)}$ on iron base alloys. Oelschlägel and Weiss ${ }^{79}$ ) showed that large elongations can be achieved in this manner. The internal stress arising in this case is from the difference in

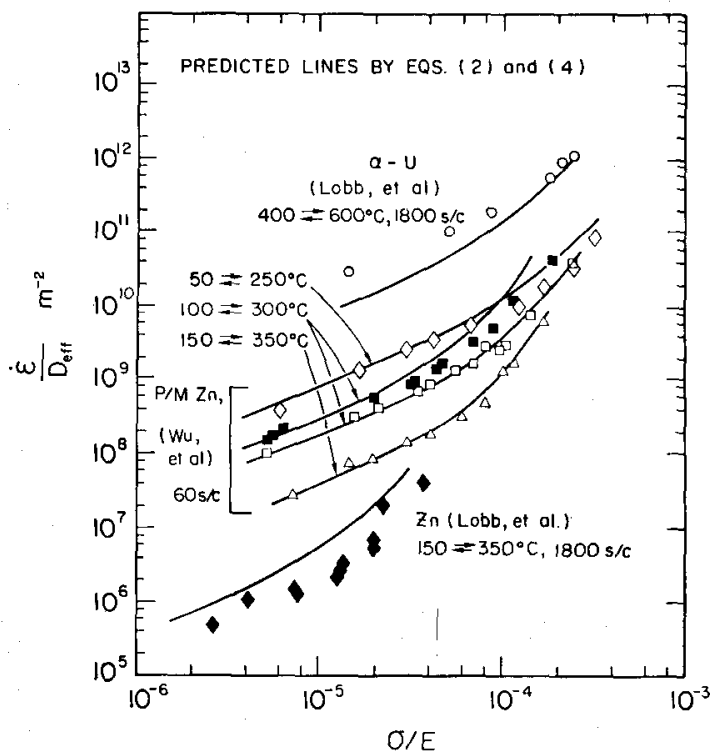

Fig. 24. Comparison of the internal stress creep model (Eqs. (2) and (4)) with all thermal cycling data available for zinc and alpha uranium. volume between the two phases during phase transformation. Such behavior is sometimes known as transformation plasticity. Application of ductility enhancement by cyclic phase transformation has been attempted with polymorphic ceramics. Many of these ceramics are based on bismuth oxides. It was shown ${ }^{80-83)}$ that high strain-rate-sensitivity exponents were obtained in many of these ceramic-base materials under thermal cycling conditions. Sherby and Wadsworth $\mathrm{h}^{4}$ have reviewed these studies and have concluded, however, that none of these ceramic systems have been shown to be superplastic. All tests were done in compression. Because tensile tests were not performed, measurements of high values of the strain-rate-sensitivity exponent, $m$, in compression are inconclusive evidence for superplasticity. This is a consequence of the fact that high values of $m$ are a necessary but insufficient criterion for superplasticity. Since polycrystalline ceramics are susceptible to grain boundary separation, it is possible that, in the ceramic oxides studied for transformation plasticity, they may well have failed with negligible ductility in tension. Clearly this uncertainty should be clarified with appropriate additional experimental studies.

Interest in phase transformation plasticity appears to have been revived recently. Notable are the studies of Nozaki et al. on iron-base alloys, ${ }^{84}$ and of Furushiro et al. on commercially pure titanium. ${ }^{85}$ ) Saotome and Iguchi ${ }^{86)}$ made in-situ microstructural observations during transformation superplasticity in pure iron, and concluded that interphase boundary sliding was an important deformation mechanism. Such studies are worthy of renewed pursuit, especially with respect to materials that are normally difficult to fabricate (such as polymorphic ceramics and intermetallic compounds). The ISS model presented earlier for describing the behavior of thermally cycled anisotropic polycrystals and metal-matrix composites may well be applicable to describing phase transformation plasticity.

\section{Enhanced Powder Consolidation through Su- perplastic Flow}

A practical method for superplastic forming of bulk material is through the use of powder metallurgy methods. The approach here is to achieve net-shaped products, with high density, by compaction of powders utilizing fine structure or internal stress superplasticity methods. Studies have been performed by Ruano et al. ${ }^{76)}$ on the use of internal stress superplasticity in enhancing the densification of white cast iron powders. Caligiuri, ${ }^{87}$ as well as Isonishi and Tokizane ${ }^{88}$ have utilized fine structure superplasticity to enhance the densification of ultrahigh carbon steel powders.

\subsection{ISS Compaction of White Cast Iron Powders}

The advent of new technologies centered on rapidly solidified powders often requires development of methods of enhancing densification wherein the fine structures present in such powders are retained. To achieve this goal it is necessary to use low tempera- 
tures, but this usually requires the application of high pressures if a high density is to be achieved. High pressures are often a limiting factor in the manufacture of powder products. One method of enhancing densification of powders is by accelerating plastic flow through the generation of internal stresses during warm pressing. As previously described, one technique for generating internal stress is through the use of multiple, solid-state phase transformations.

Ruano et al. ${ }^{76)}$ showed that the densification of rapidly solidified white cast iron powders was enhanced by multiple phase transformations. The basis of this result is that during phase transformation volume changes occur which create internal stresses. These internal stresses assist plastic flow, and result in enhanced pressure-sintering kinetics. An example of such a result is shown in Fig. 25. The densification kinetics of white cast irons are shown as a function of applied stress under both isothermal and thermal cycling conditions. The results demonstrate that thermal cycling, under stress, is an important factor in enhancing densification. For example, under a very low externally-applied stress of $6.9 \mathrm{MPa}$, a density of $95 \%$ is found for 10 cycles, and a density of $90 \%$ is found for one cycle. By contrast, densities of much less than $80 \%$ are found for the isothermally warm-pressed samples at both 650 and $775^{\circ} \mathrm{C}$. Transformation cycling is also seen to enhance the densification of white cast iron powders at high applied stresses. For example, at $20 \mathrm{MPa}$, a density of about $99 \%$ is found for 10 cycles and about $95 \%$ for one cycle. Without transformation cycling, a density of only $90.5 \%$ is found after warm pressing for $0.5 \mathrm{~h}$ at $775^{\circ} \mathrm{C}$ and less than $80 \%$ is found after warm pressing for $0.5 \mathrm{~h}$ at $650^{\circ} \mathrm{C}$. The results shown in Fig. 25 indicate that high densification can be achieved in a short time by utilizing transformation cycling under

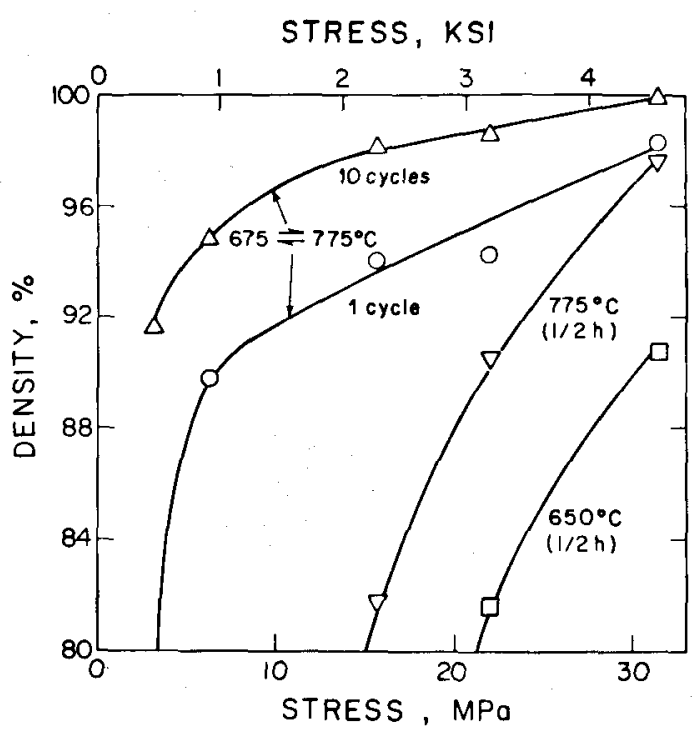

Fig. 25. Influence of multiple phase transformations (internal stress superplasticity) on the densification of white cast iron powders as a function of stress. High densities are achieved at low applied stresses under thermal cycling conditions. small applied stresses.

\subsection{FSS Compaction of Ultrahigh Carbon Steel Powders}

Caligiuri ${ }^{87}$ ) studied the pressure-sintering kinetics of metal powders. Specifically, the kinetics of pressure sintering of ultrahigh carbon steel $(1.6 \% \mathrm{G})$ powders containing either coarse-grained (non-superplastic) structures or fine-grained (superplastic) structures were investigated. For comparison, the pressure sintering kinetics of iron powders were also investigated. In order to interpret the densification mechanisms of powders under an applied stress, the creep behavior of the ultrahigh carbon steels containing coarse and fine microstructures was established. The creep rate of the fine-grained steel at a given stress was higher than the creep rate of the coarse-grained steel. The densification of coarse- and fine-grained UHCS powders was found to parallel their creep behavior. The fine-grained powders densified more readily than the coarse-grained powders. From these results, it was concluded that a superplastic microstructure enhances densification and permits the pressing of powders into high density compacts at intermediate temperatures and low pressures. From the densification and creep studies, Caligiuri developed an equation which showed that the intermediate-stage densification rate $(\dot{\rho})$ can be related to the steady-state creep rate $\left(\dot{\varepsilon}_{\mathrm{ss}}\right)$ at a given temperature by:

$$
\dot{\rho}=A[(1-\rho) / \rho]^{n} \dot{\varepsilon}_{\mathrm{ss}}
$$

where, $n:$ the stress exponent

$A$ : a constant (of value 57).

Thus, for a fixed value of relative density, the densification rate at a given intermediate temperature and low pressure is directly proportional to the steady state creep rate of the material (under the same conditions of testing) and to the stress exponent of the material. Through Eq. (5), the densification behavior of a material can be predicted by simply knowing its creep properties at the temperature and pressure of interest.

Since superplastic materials generally creep faster than non-superplastic materials, at intermediate temperatures and low stresses, Eq. (5) predicts that superplastic materials will densify faster than non-superplastic materials during pressing. Furthermore, the relationship between densification rate and creep rate predicts that, through the term $[(1-\rho) / \rho]^{n}$, superplastic materials (low stress exponent) will densify faster than non-superplastic materials (high stress exponent) at the same creep rate. This prediction was verified experimentally. First, creep experiments were performed to determine the stress, at $650^{\circ} \mathrm{C}$, at which a superplastic $1.6 \%$ C steel has the same steady state creep rate as a non-superplastic commercially pure iron. [This stress was determined to be $43.1 \mathrm{MPa}$ at $650^{\circ} \mathrm{C}$.] Powders of these materials were then compacted at $43.1 \mathrm{MPa}$. The results of these experiments are shown in Fig. 26. The $1.6 \%$ C superplastic powders densify more rapidly than the iron powders. 


\section{Superplastic Laminated Composites}

An important property of fine-grained superplastic materials is that they are often readily bonded in the solid state, either to themselves or to other non-superplastic materials. This bonding is possible because of the presence of many grain boundaries in the finegrained material which act as short-circuit paths for diffusion. ${ }^{89}$ The same materials, if coarse-grained, will not readily bond under identical conditions of pressure, temperature, and time.

The ease of solid-state bonding in fine-grained UHC steels makes it possible to prepare ferrous laminated composites with sharp interfaces between layers. Discrete interlayer boundaries are achieved because the laminated composites are prepared by roll bonding at low temperatures (e.g., $650^{\circ} \mathrm{C}$ ). Such laminated composites have been shown to exhibit unique impact and superplastic properties. For example, very low ductile-to-brittle transition temperatures $\left(-140^{\circ} \mathrm{C}\right)$ are obtained in a UHC steel/mild steel laminated composite in Charpy $V$-notch impact tests. ${ }^{90}$ This is attributed to notch blunting of the crack by delamination at the layer interfaces. An-

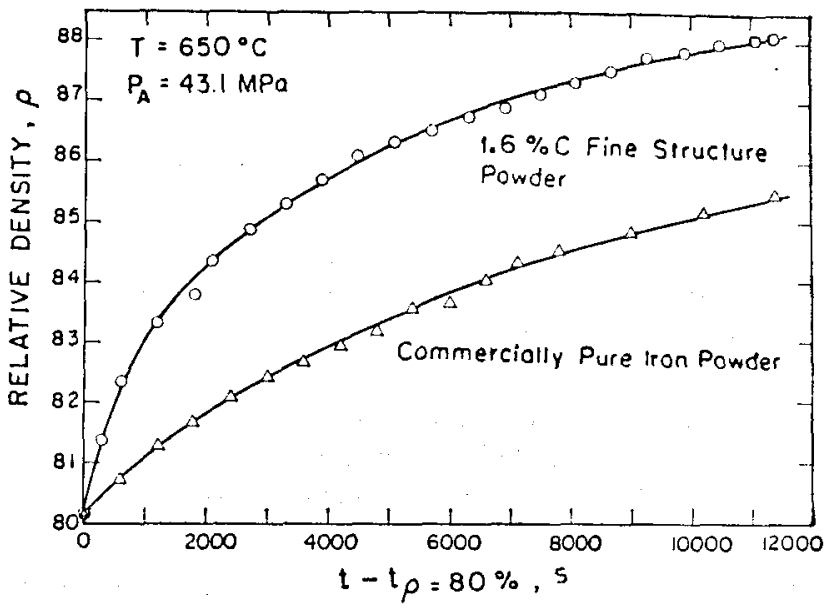

Fig. 26. Relative density-time curves for fine-grained $\mathbf{1 . 6}$ $\%$ G UHC steel powders and commercially-pure iron powders compacted at $650^{\circ} \mathrm{C}$.

A constant applied pressure of $43.1 \mathrm{MPa}$ was used, at which stress the creep rates of the two dissimilar materials are identical.

The data is for the intermediate stage of compaction. other useful characteristic of the UHC steel laminated composite is its intermediate temperature ductility properties. Thus, it is possible to make non-superplastic mild steel behave in a superplastic-like manner at intermediate temperatures by lamination to superplastic UHC steel. ${ }^{91}$ ) Strain-rate sensitivity exponents over 0.30 and elongations to fracture of over $400 \%$ were obtained. The strain rate-stress results show good agreement with constitutive equations for creep based on an isostrain deformation model. This model was used to predict the conditions of strain rate, temperature, and the percentage of non-superplastic component required to achieve nearly ideal superplasticity in a ferritic stainless steel clad to a UHC steel. Daehn et al. ${ }^{92)}$ have shown that the predicted conditions are achieved at $825^{\circ} \mathrm{C}$ and at $\dot{\varepsilon}=10^{-3} \mathrm{~s}^{-1}$ for a UHC steel clad with a ferritic stainless steel (12\% by volume). This combination of components and test conditions leads to the unexpected result that coarse-grained stainless steels can be made superplastic as shown in Fig. 27.

\section{Acknowledgements}

The author wishes to express his sincerest thanks to the many colleagues that have collaborated with him on the subject of superplasticity. He is especially grateful to Dr. Jeffrey Wadsworth, with whom he has worked very closely and who has been so instrumental in developing many of the new concepts and findings described in this paper. The author gives thanks to Professor T. R. McNelley for permission to use Figs. 13 to 15 prior to publication. Discussions with Dr. G. González proved most helpful and are sincerely appreciatcd. Much of the work of the author and his colleagues has been sponsored by two agencies, the Office of Naval Research and the Army Research Office. Their interest and faith in our work is sincerely appreciated.

\section{REFERENCES}

1) J.W. Edington, K. N. Melton and C. P. Cutler: Prog. Mater. Sci., 21 (1976), No. 2, 61.

2) O. D. Sherby and J. Wadsworth: Deformation Processing and Structure, ed. by G. Krauss, Am. Soc. Met., Metals Park, OH, (1984), 355.

3) O. D. Sherby and J. Wadsworth: Mater. Sci. Technol., 1 (1985), 925.

4) O. D. Sherby and J. Wadsworth: Superplasticity in Aero-

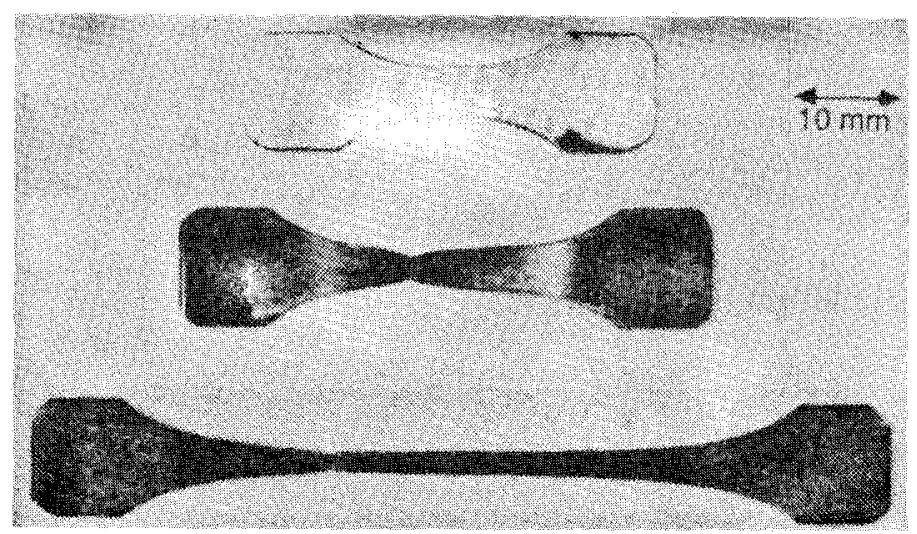

Fig. 27.

Ferritic stainless steel samples in three conditions. The top specimen is in the untested condition. The center specimen is stainless steel tested at $825^{\circ} \mathrm{C}$ and at $\dot{\varepsilon} \sim 10^{-3} \mathbf{s}^{-1}$.

The bottom specimen is stainless steel clad to fine-grained ultrahigh carbon steel tested at $825^{\circ} \mathrm{C}$ and at $\dot{\varepsilon} \sim 10^{-3} \mathrm{~s}^{-1}$. 
space, ed. by T. R. McNelley and H. Charles Heikkenen, Metall. Soc., Inc., Warrendale, PA, (1988), 3.

5) G. D. Bengough: J. Inst. Met., 7 (1912), 123.

6) E. Geckinli: Technical University of Istanbul, Istanbul, Turkey, (Private Communication, Dec. 1987).

7) W. A. Backofen, I. R. Turner and D. H. Avery: Trans. Am. Soc. Met., 57 (1964), 980.

8) The Guiness 1983 Book of World Records, ed. by N. McWhirter, Marca Registrada, Bantam Books, Inc., New York, NY, (1983), 144.

9) M.M.I. $\Lambda$ hmed and T. G. Langdon: Metall. Trans. A, 8A (1977), 1832.

10) K. Higashi, T. Ohnishi and Y. Nakatani: Scr. metall., 19 (1985), 821

11) Superplastic Forming of Structural Alloys, ed. by N. E. Paton and C.H. Hamilton, AIME, Warrendale, PA, (1982).

12) Superplastic Forming, ed. by S. P. Agrawal, Am. Soc. Met., Metals Park, OH, (1985).

13) Procecdings of the International Conference on Superplasticity in Aerospace-Aluminum, ed. by R. Pearce and L. Kelly, Ashford Press, Southampton, England, (1985).

14) Superplasticity, ed. by B. Baudelet and M. Suery, Editions CNRS, Paris, (1985).

15) Supcrplasticity, AGARD/NATO Lecture Series, No. 154, Nat. Tech. Inform. Serv., Springfield, VA, (1987).

16) Superplasticity in Aerospace, ed. by T. R. McNelley and H. Charles Heikkenen, Metall. Soc., Inc., Warrendale, PA, (1988).

17) Proceedings of Cino-Japan Joint Symposium on Superplasticity, Beijing, (1985).

18) Proceedings of China-Japan Joint Symposium on Superplasticity, Yokohama, (1986).

19) C. A. Henshall, J. Wadsworth, M. J. Reynolds and A. J. Barnes: Materials and Design, 8 (1987), 324.

20) P. G. Partridge: Superplasticity, NATO/AGARD Lec. Ser., No. 154, Nat. Tech. Inform. Serv., Springfield, VA, (1987), 5-1.

21) B. W. Kim and S. P. Agrawal: Northrop Aircraft, Hawthorne, CA, (Private Communication).

22) D. Stephen: Superplasticity, NATO/AGARD Lec. Ser., No. 154, Nat. Tech. Inform. Serv., Springfield, VA, (1987), 7-1.

23) J. B. Moore, J. Tequesta and R. L. Athey: U.S. Patent 3,519,503, (1976).

24) R. Pearce and E.W.J. Miller: Superplastic Forming of Structural Alloys, ed. by N. E. Paton and C. H. Hamilton, AIME, Warrendale, PA, (1892), 375.

25) Yang Chun-Xiao: Proceedings of Cino-Japan Joint Symposium on Superplasticity, Beijing, (1985), 66

26) F. Wakai, S. Sakaguchi and Y. Matsuno: Advanced Ceram. Mater., 1 (1986), 259.

27) F. Wakai and H. Kato: Advanced Ceram. Mater., 2 (1987), 71.

28) J. W. Chung and J. R. Cahoon: Met. Sci. J., 13 (1979), 635.

29) O. A. Ruano, L. E. Eiselstein and O. D. Sherby: Metall. Trans. A, 13A (1982), 1785.

30) Y. Maehara: Trans. Iron Steel Inst. Jpn,, 27 (1987), 705.

31) D. W. Kum, G. Frommeyer, N. J. Grant and O. D. Sherby: Metall. Trans. A, 18A (1987), 1703.

32) J. Wadsworth, T. Oyama and O. D. Sherby: 6th InterAmerican Conference on Materials Technology, II, ed. by I. Le May, ASME, New York, (1980), 29.

33) J. Wadsworth, J. H. Lin and O. D. Sherby: Met. Technol., 8 (1981), 190.

34) J. J. Gilman: in Mechanical Behavior of Crystalline Solids, Nat. Bureau of Standards, Monograph 59, (1963), 79.
35) T. G. Nieh, C. A. Henshall and J. Wadsworth: Scr. metall., 18 (1984), 1405.

36) J. Wadsworth, C. A. Henshall, T. G. Nieh, A. R. Pelton and P.S. Gilman: High Strength Powder Metallurgy Aluminum Alloys, II, ed. by G.J. Hildeman and M. J. Koczak, AIME, Warrendale, PA, (1986), 137.

37) T. G. Nieh, P. S. Gilman and J. Wadsworth: Scr. metall., 19 (1985), 1375.

38) T. R. Bieler, T. G. Nieh, J. Wadsworth and O. D. Sherby: Scr. metall., 22 (1988), 81.

39) J. K. Gregory, J. C. Gibeling and W. D. Nix: Metall. Trans, A, 16A (1985), 777.

40) O. D. Sherby and P. M. Burke: Prog. Mater. Sci., 13 (1967), 325.

41) H. Watanabe, K. Ohori and Y. Takeuchi: Trans. Iron Steel Inst. Jpn., 27 (1987), 730.

42) A. Salama and T. McNelley: research in progress, (1989); A. Salama: Ph.D. Dissertation, U.S. Naval Postgraduate School, Monterey, CA, (1987).

43) K.A. Padmanabhan and G. J. Davies: Superplasticity, Springer-Verlag, Berlin, (1980).

44) D. Shin, D. A. Selby, J. Belzunce, J. Roberts and O. D. Sherby: ONR Tech. Rep., Program N00014-82-K-0314, Stanford University, (1987).

45) A. Ball and M. M. Hutchinson: Met. Sci.J., 3 (1969), 1.

46) A. K. Mukherjee: Mater. Sci.Eng., 8 (1971), 83.

47) T. G. Langdon: Phil. Mag., 22 (1970), 689.

48) R. C. Gifkins: Metall. Trans. A, 7A (1976), 1225.

49) M. F. Ashby and R. A. Verrall: Acta metall., 21 (1973), 149.

50) D. Grivas, J. W. Morris, Jr. and T. G. Langdon: Scr. metall., 15 (1981), 229.

51) A. Arieli and A. K. Mukherjee: Scr. metall., 15 (1981), 237.

52) O. A. Kaibyshev: Czech. J. Phys., 31B (1981), 2613.

53) G. Rai and N. J. Grant: Metall. Trans. A, 6A (1975), 385.

54) M.J. Mayo: Ph.D. Disscrtation, Dept, of Materials Science and Engineering, Stanford University, (1988).

55) H. Fukuyo, T. Oyama, H. G. Tsai and O. D. Sherby: research in progress, (1989); H. Fukuyo: Engineer Dissertation, Dept. of Materials Science and Engineering, Stanford University, (1987).

56) W. R. Cannon and O.D. Sherby: Metall. Trans. A, 1 A (1970), 1030.

57) C. H. Hamilton, A. K. Ghosh and M. M. Mahoney: Advanced Processing Methods for Titanium, ed. by D.F. Hasson and C. H. Hamilton, Met. Soc. of AIME, Warrendale, PA., (1982), 129.

58) C. H. Hamilton and A. K. Ghosh: Metall. Trans. A, 11A (1980), 1494.

59) D. Lee: Acta metall., 17 (1969), 1057.

60) D. L. Holt and W. A. Backofen: Trans. Am. Soc. Met., 59 (1966), 755.

61) R. Horiuchi, A. B. El-Sebai and M. Otsuka: Scr. metall., 7 (1973), 1101.

62) H.W. Hayden, R. C. Gibson, H. P. Merrick and J. H. Brophy: Trans. Am. Soc. Met., 60 (1967), 3.

63) M. Suery and B. Baudelet: Phil. Mag. A, 41 (1980), 41.

64) H.W. Hayden, S. Floreen and P. D. Goodall: Metall. Trans. A, 3A (1972), 833.

65) H. E. Cline and D. Lee: Acta metall., 18 (1970), 315.

66) M.Y. Wu and O. D. Sherby: Scr. metall., 18 (1984), 773.

67) M. Y. Wu: Ph.D. Dissertation, Dept. of Materials Science and Engineering, Stanford University, (1984).

68) M. Y. Wu, J. Wadsworth and O. D. Sherby: Scr. metall., 21 (1987), 1159.

69) G. González-Doncel, S. D. Karmarkar, A. P. Divecha and O. D. Sherby: Composite Sci. Technol., 35 (1989), in press.

70) S. H. Hong, O. D. Sherby, A. P. Divecha, S. D. Karmarkar 
and B. A. MacDonald: J. Composite Mater, 22 (1988), 102.

71) R. C. Lobb, E. C. Sykes and R. H. Johnson: Met.Sci.J., $6(1972), 33$.

72) M. Y. Wu, J. Wadsworth and O. D. Sherby: Metall. Trans. $A, 18$ A (1987), 451.

73) A. Sauveur: Iron Age, 113 (1924), 581.

74) M. de Jong and G. W. Rathenau: Acta metall., 9 (1961), 143.

75) F. Cilinard and O. D. Sherby: Acta metall., 12 (1964), 911.

76) O.A. Ruano, J. Wadsworth and O.D. Sherby: Metall. Trans. $A$, 13A (1982), 355.

77) F. Garofalo: Trans. TMS-AIME, 227 (1963), 351.

78) G. Wasserman: Arch. Eisenhültenwes, 6 (1933), 347.

79) D. Oelschlägel and V. Weiss: Trans. Am. Soc. Met., 59 (1966), 143.

80) J. R. Smythe, R. C. Bradt and J. H. Hoke: J. Am. Ceram. Soc., 58 (1975), 381.

81) J. R. Smythe, R. C. Bradt and J. H. Hoke: J. Mater. Sci., 12 (1977), 1495.

82) L. A. Winger, R. C. Bradt and J. H. Hoke: J. Am. Ceram. Soc., 63 (1980), 291.

83) C. A. Johnson, R. C. Bradt and J. H. Hoke: J. Am. Ceram. Soc., 58 (1975), 37.

84) H. Nozaki, Y. Uesugi, 'T. Okada and I. Tamura: J.Jpn.
Inst. Met., 50 (1986), 56.

85) N. Furushiro, H. Kuramoto, Y. Takayama and S. Hori: Trans. Iron Steel Inst. Jpn., 27 (1987), 725.

86) Y. Saotome and N. Iguchi: Trans. Iron Steel Inst. Jpn., 27 (1987), 696.

87) R. D. Caligiuri: Ph.D. Dissertation, Dept. of Materials Science and Engineering, Stanford University, (1977).

88) K. Isonishi and M. Tokizane: J.Jpn. Inst. Met., 49 (1985), 149.

89) O. D. Sherby, J. Wadsworth, R. D. Caligiuri, L. E. Eiselstein, B. C. Snyder and R. T. Whalen: Scr. metall, 13 (1979), 941.

90) D. W. Kum, T. Oyama, J. Wadsworth and O. D. Sherby: J. Mech. Phys. Solids, 31 (1983), 173.

91) B. C. Snyder, J. Wadsworth and O. D. Sherby: Acta metall., 32 (1984), 919.

92) G. Daehn, D. W. Kum and O. D. Sherby: Metall. Trans. $A, 17$ A (1986), 2295.

(Based on the Yukawa Memorial Lecture delivered by Dr. O. D. Sherby at the 115th ISIJ Meeting, April 1, 1988, at Chiba Institute of Technology in Narashino) 